\title{
DIE VEREINTEN NATIONEN UND DIE NUTZUNG DES BODENS UND UNTERGRUNDES \\ DES HOHEN MEERES AUSSERHALB DER GRENZEN NATIONALER HOHEITSGEWALT
}

\author{
Von Max Ivers KeHden
}

Meeresboden und -untergrund in Gewässern außerhalb der Grenzen nationaler Hoheit ${ }^{1}$ erscheinen auf den ersten Blick kaum als geeignetes Thema für Beratungen in den Vereinten Nationen. Erzeugt doch selbst heute noch der Gedanke an eine Ausbeutung ihrer Naturschätze, um nur eine Nutzungsmöglichkeit zu nennen, eher Assoziationen an eine gewisse Art von Literatur, für die sich die Bezeichnung "science-fiction“ eingebürgert hat. In einer Zeit, in der zwar die Landung des Menschen auf dem Mond nur noch eine Frage von Monaten zu sein scheint, aber kein Mensch je den Boden der Tiefsee betreten hat, ist das auch nicht weiter verwunderlich. Noch dazu, wenn selbst über entferntere Himmelskörper ein umfangreiches Wissen angesammelt werden konnte, während der Boden der Tiefsee - fast dreimal so groß wie die gesamte Festlandmasse der Erde - kaum mehr als eine blaue Fläche auf dem Globus geblieben zu sein scheint. Eine Nutzung des Bodens und Untergrundes der Tiefsee ist jedoch keineswegs mehr so utopisch, wie es noch vor wenigen Jahren den Anschein hatte, besonders seit man die militärische Bedeutung der unterseeischen Gebiete erkannt und ihre Erforschung entsprechend intensiviert hat ${ }^{2}$. Mehr noch fast als die Notwendigkeit einer besseren Regelung der friedlichen Nutzung dürfte auch der Wunsch, eine militärische Nutzung und ein neues Wettrüsten ${ }^{3}$ zu verhindern, der Antrieb für die seit kurzem auf diesem Gebiet zu beobachtende Aktivität der Vereinten Nationen sein.

Vieles deutet allerdings darauf hin, daß das Problem der militärischen Nutzung gleichzeitig das größte Hemmnis für einen erfolgreichen Abschluß dieser Bemühungen bildet. Aber auch die nur mit einer friedlichen Nutzung zusammenhängenden Fragen werden trotz der unlängst erfolgten Einsetzung eines Ausschusses für die friedliche Nutzung des Meeresbodens außerhalb der Grenzen nationaler Jurisdiktion ${ }^{5}$ wohl kaum so bald befriedigend gelöst werden können ${ }^{6}$. Technik und Wissenschaft sind nämlich in diesem Bereich in einer so schnellen Entwicklung begriffen, daß maßgebliche Staaten noch nicht bereit sind, zu

$1 \mathrm{Im}$ folgenden als Boden und Untergrund der Tiefsee bezeichnet.

2 In welchem Maße das geschehen ist, verdeutlichen am besten folgende Zahlen: Für das ozeanische Forschungsprogramm des amerikanischen Verteidigungsministeriums wurden am Anfang dieses Jahrzehnts wenige Millionen Dollar jährlich ausgegeben, im Jahre 1966 bereits 165 Millionen und im Jahre 1969 sogar 287 Millionen Dollar, vgl. Hersh, Seymour M.: An Arms Race on the Sea Bed?, in: War/Peace Report, Bd. 8 (1968), Nr. 7, S. 8-9, 21-22 (8f.).

3 Erste Ánfänge eines solchen Wettrüstens werden bereits sichtbar, vgl. Hersh, a. a. O.

4 Allerdings gibt es in dem Weltraum-Vertrag vom 19. 12. 1966 einen Präzedenzfall für eine Entmilitarisierung, der von vielen als Vorbild für die Regelung der militärischen Nutzung des Tiefsee-Bodens und -Untergrundes angesehen wird; vgl. Levy, Jean-Pierre: Regelung der Besitz- und Nutzungsrechte des Meeresgrundes, in: Osterreichische Zeitschrift für Außenpolitik, Bd. 8 (1968), S. 135-148 (145); ebenso Swirin, Eduard: Regelung über den Festlandsockel der Ostsee in: Neue Zeit (Moskau), Bd. 26 (1968), Nr. 47, S. 6-7, für den Festlandsockel.

5 Vgl. die Resolution 2467 A (XXIII) der Vollversammlung vom 21. 12. 1968 (Englischer Text: UN Monthly Chronicle, Bd. 6 (1969), Nr. 1, S. 58)

6 Ist es doch schon auf der von den Vereinten Nationen einberufenen Genfer Seerechtskonferenz des Jahres 1958 nicht einmal gelungen, sich auf eine Begriffsbestimmung für den Festlandsockel im rechtlichen Sinne zu einigen, die diese Bezeichnung auch verdient. Eine klare Abgrenzung zwischen dem unter inhaltlich beschränkter Hoheitsgewalt der Küstenstaaten stehenden Festlandsockel und dem Boden der Tiefsee ist jedoch für die Regelung der hier anstehenden Fragen unerläßlich. 
den damit aufgeworfenen rechtlichen Fragen definitiv Stellung zu nehmen? Ebensowenig dürfte der Egoismus der Küstenstaaten, welcher als Hauptantrieb für die in der Nachkriegszeit zu verzeichnende beträchtliche Ausweitung der unter nationaler Hoheitsgewalt stehenden Meereszonen anzusehen ist ${ }^{8}$, der Arbeit der Vereinten Nationen förderlich sein. Richtet man schließlich sein Augenmerk darauf, daß auf absehbare Zeit nur einige große Industrienationen über die wirtschaftlichen und technischen Mittel für eine Nutzung des Tiefsee-Bodens und -Untergrundes verfügen werden und sich diesen Wettbewerbsvorteil erhalten werden wollen, so sind die drei wesentlichen Hindernisse für eine vertragliche Regelung der friedlichen Nutzung genannt ${ }^{9}$.

\section{I.}

Auf jeden Fall ist es zu begrüßen, daß der angesprochene Problemkreis überhaupt von einem internationalen Gremium erörtert wird. Wenn man nämlich in die sich hier anbahnende Entwicklung nicht regelnd eingreift, ist zu befürchten, daß der Boden und Untergrund der Tiefsee bald Gegenstand heftiger Auseinandersetzungen sein werden. Und zwar könnten sich demgegenüber die Fischereistreitigkeiten der Gegenwart, bei denen selbst der Einsatz von Kriegsschiffen leider keine Seltenheit mehr ist ${ }^{10}$, als ausgesprochen harmlos erweisen. Daß die Lösung zumindest einiger grundlegender Fragen, die bisher zutage getreten sind, keinen allzu langen Aufschub mehr duldet, muß bei einer Extrapolation der bisherigen Entwicklung in die Zukunft als sehr wahrscheinlich angesehen werden. Sie war nämlich durch ein geradezu exponentielles Anwachsen des Wissens und der technischen Möglichkeiten gekennzeichnet, und alles deutet darauf hin, daß sie noch längere Zeit in der gleichen Weise verlaufen wird.

Ein anschauliches Bild dieser Entwicklung liefert die Geschichte der Meeresforschung, die zugleich auch eine Geschichte der Meerestechnik ist, da beide in enger Beziehung zueinander stehen ${ }^{11}$. Erste Anfänge der Meeresforschung sind bereits im Altertum $\mathrm{zu}$ beobachten ${ }^{12}$, ohne daß jedoch in den folgenden Jahrhunderten nennenswerte Forschritte $\mathrm{zu}$ verzeichnen sind. Mit einer intensiveren Erforschung der Weltmeere wurde auch erst in der zweiten Hälfte des vorigen Jahrhunderts begonnen. Merkwürdigerweise ging der Antrieb hierzu von einer Nutzungsmöglichkeit aus, die heute in den Hintergrund der Überlegungen getreten ist, obwohl sie auch im Zeitalter der Nachrichtensatelliten nicht an Bedeutung verloren hat ${ }^{13}$, nämlich die transozeanische Nachrichtenübermittlung mittels unter-

7 Vgl. Pardo, Arvid: Whose is the Bed of the Sea? Address at the Fourth Session of the Sixty-Second Annual Meeting of the American Society of International Law held at Washington, D. C. April 25-27, 1968, in: Proceedings of the American Society of International Law, 1968, S. 216-229 (223). Im folgenden zitiert als Address.

8 Vgl. Kehden-Henkmann: Die Inanspruchnahme von Meereszonen durch Küstenstaaten - Eine Ubbersicht über die Staatenpraxis nach dem Stande vom 1. Juni 1967, Hamburg 1967. Seit Erscheinen dieses Werkes haben Argentinien, Australien und Frankreich Fischereizonen von $12 \mathrm{sm}$ Breite geschaffen, Indien und Kuwait ihr Küstenmeer auf $12 \mathrm{sm}$ ausgedehnt und ist in Senegal eine Erweiterung des Küstenmeeres auf $12 \mathrm{sm}$ in Vorbereitung.

9 Zusammen mit dem Bestreben einiger Staaten, die Nutzung des Bodens und Untergrundes der Tiefsee unter eine internationale Kontrolle zu bringen, sind damit gleichzeitig die vier Grundhaltungen angedeutet, die bei der Erörterung dieses Problemkreises bisher in Erscheinung getreten sind. Francis T. Christy. jr. hat sie mit den anschaulichen Etiketten "wait and see “ approach, "national lake“ approach, "flag nation" approach und "international regime“ approach versehen und eingehend analysiert; vgl. Pardo, Address, S. $223 \mathrm{f}$.

$10 \mathrm{Vgl}$. zum Beispiel die Aufstellung des amerikanischen Innenministeriums über die Behinderung des Thunfischfangs an der südamerikanischen Westküste in den Jahren 1951 bis 1963, in: International Legal Materials 1964, S. 61.

11 Vgl. Keil, Alfred: Meerestechnik, in: Hansa, Bd. 105 (1968), S. 2176-2178.

$12 \mathrm{Kein}$ geringerer als Aristoteles hat schon eingehende meeresbiologische Studien getrieben; vgl. Cowen, Robert C.: Frontiers of the Sea, London 1960, S. 22.

13 Das ergibt sich schon aus der Tatsache, daß auch heute noch solche Kabel neu verlegt werden. So wurde 
seeischer Telegraphenkabel. Für die Verlegung dieser Kabel war es erforderlich, exakte Kenntnisse über Meerestiefen, Form und Beschaffenheit des Meeresbodens, Strömungsverhältnisse, Wassertemperatur in den verschiedenen Tiefen und viele andere Daten mehr zu erlangen. Zunächst wurden einige kleinere Forschungsreisen unternommen. Diese lieferten schon eine solche Fülle von Erkenntnissen, daß schnell die Notwendigkeit größerer Unternehmungen erkannt wurde ${ }^{14}$. Die erste Fahrt dieser Art wurde von der britischen Korvette "Challenger" durchgeführt. Ihre dreieinhalbjährige Weltumsegelung, auf welcher systematisch in allen Ozeanen Messungen der verschiedensten Art vorgenommen wurden, in großen Tiefen nach Lebewesen geforscht wurde sowie Bodenproben vom Meeresgrund heraufgeholt und analysiert wurden, legte den Grundstein für eine umfassende wissenschaftliche Erforschung der Weltmeere ${ }^{15}$. Der 7. Dezember 1872, an dem die "Challenger" auslief, kann daher als Beginn der modernen Meeresforschung angesehen werden. Von der Unzahl überraschender Erkenntnisse, die auf dieser Expedition gewonnen wurden, sei in diesem Zusammenhang nur die Entdeckung eisen- und manganhaltiger Ablagerungen auf dem Boden der Tiefsee genannt ${ }^{16}$. Sie waren der erste Hinweis darauf, daß auch im Meeresboden Vorkommen an Erzen und sonstigen Naturschätzen vorhanden seien, die man eines Tages bei einem entsprechenden Fortschritt der Technik würde abbauen können. Die Ergebnisse der Meeresforschung und die Entwicklung der Meerestechnik in den folgenden Jahrzehnten sollten diese Vermutung nicht nur bestätigen, sondern schon bald alle Erwartungen übertreffen.

Es ist hier nicht der Ort, die historische Entwicklung im einzelnen nachzuzeichnen ${ }^{17}$. Einige besonders bemerkenswerte Ereignisse und Forschungsergebnisse seien jedoch herausgegriffen, um wenigstens eine ungefähre Vorstellung davon zu geben, mit welcher Schnelligkeit die technischen Möglichkeiten verbessert und die Kenntnisse vervollkommnet wurden und wie erfolgreich die Entwicklung bisher verlaufen ist. Noch in der Mitte des vorigen Jahrhunderts wurde allen Ernstes die Auffassung vertreten, das spezifische Gewicht des Meerwassers erhöhe sich mit zunehmender Wassertiefe, und zwar in großer Tiefe so beträchtlich, $\mathrm{daß}$ auch schwerere Gegenstände nicht bis auf den Boden der Ozeane absinken würden ${ }^{18}$. Keine hundert Jahre später, nämlich schon im Jahre 1934, tauchten William Beebe und Otis Barton mit einer von einem Schiff an einem Seil herabgelassenen Stahlkugel bis auf eine Tiefe von über $900 \mathrm{~m}^{19}$. Dann vergingen nur noch zwanzig Jahre, bis Georges Houot und Pierre Willm in einem von August Piccard entwickelten Bathyscaph vor Dakar in einer Tiefe von rund $4000 \mathrm{~m}$ als erste den Boden der Tiefsee erreichten ${ }^{20}$. Und nur noch sechs Jahre später, am 22. Januar 1960, tauchten Jacques Piccard und Donald Walsh mit dem Bathyscaph "Trieste“ sogar bis auf den Grund des Marianengrabens, dessen Tiefe von fast $11000 \mathrm{~m}$ nur noch von der des Mindanaograbens übertroffen wird ${ }^{21}$. All diese Unternehmungen stellten jedoch nicht nur groß-

am 22. 11.1967 mit der Verlegung eines Kabels zwischen Südafrika und Europa und am 13. 1.1968 mit der Verlegung eines Kabels zwischen Marseille und Tel Aviv begonnen; vgl. Rousseau, Charles: Chronique des faits internationaux, in: Revue générale de droit international public, Bd. 72 (1968), S. $750,806$.

14 Vgl. dazu Cowen, a. a. O., S. $27 \mathrm{ff}$.; Cromie, William J.: Exploring the Secrets of the Sea, Englewood Cliffs 1962 , S. $34 \mathrm{ff}$.

15 Vgl. hierzu u. a. die Reisebeschreibung von Spry, W. J. J.: Die Expedition des Challenger, Leipzig 1877. 16 Vgl. Spry, a. a. O., S. $34 \mathrm{f}$.

17 Hierzu sei außer auf die genannten Werke von Cowen und Cromie u. a. auf Soule, Gardner: The Ocean Adventure, New York 1966 (mit umfangreichen Literaturnachweisen) verwiesen.

18 Vgl. Spry, a. a. O., S. 1.

19 Vgl. Soule, a. a. O., S. $106 \mathrm{ff}$.

20 Vgl. Cowen, a. a. O., S. $270 \mathrm{ff}$.

$21 \mathrm{Vgl}$. Soule, a. a. O., S. $187 \mathrm{ff}$. 
artige technische Pionierleistungen dar, sondern lieferten zusammen mit den Fahrten von Úberwasserschiffen, von denen vor allem die des deutschen Forschungsschiffes „Meteor" von 1925 bis $1927 \mathrm{zu}$ nennen ist², eine Fülle von wissenschaftlichen Erkenntnissen.

In der Gegenwart arbeitet man an einer Vielzahl neuartiger Forschungsprogramme. Eines dieser Projekte besteht darin, Tauchfahrzeuge zu entwickeln, mit denen man unter anderem in der Lage ist, bis auf den Boden der Tiefsee hinabzutauchen, dort aufzusetzen und mit besonderen Greifvorrichtungen dem Boden Proben $\mathrm{zu}$ entnehmen oder andere Arbeiten auszuführen ${ }^{23}$. Die hierzu konstruierten Forschungsunterseeboote zeichnen sich gegenüber den Tauchkugeln und den Bathyscaphs durch einen größeren horizontalen Aktionsradius aus. Eines der ersten Fahrzeuge dieser Art ist die amerikanische "Alvin“. In ihr tauchten William O. Rainnie, Jr., und Marvin J. McCamis am 20. Juli 1965 in der Nähe der Bahamas auf den Grund des Atlantischen Ozeans, der dort rund $1800 \mathrm{~m}$ tief ist, und „parkten“ das Fahrzeug längere Zeit auf dem Meeresboden ${ }^{24}$. Später bewies die "Alvin“ in spektakulärer Weise ihre Eignung für Arbeiten in der Tiefsee, als sie im Jahre 1966 vor der spanischen Küste in über $900 \mathrm{~m}$ Tiefe auf dem Meeresboden eine bei einem Flugzeugabsturz verloren gegangene Wasserstoffbombe wieder auffand, die dann von einem unbemannten Unterwasserfahrzeug geborgen wurde ${ }^{25}$. Die ebenfalls in den Vereinigten Staaten gebaute "Aluminaut" ist für Forschungsarbeiten bis in $4500 \mathrm{~m}$ Tiefe konstruiert und hat schon am 11. November 1965 die von der "Alvin“ erreichte Tauchtiefe um $75 \mathrm{~m}$ übertroffen. Sie kann maximal drei Tage unter der Meeresoberfläche bleiben und hat bereits eine Tauchfahrt von 33 Stunden Dauer durchgeführt, bei der sie über $100 \mathrm{~km}$ in großer Tiefe zurücklegte. Welche Möglichkeiten ein solches Fahrzeug eröffnet, zeigte sich im Sommer 1966, als die "Aluminaut" zehn Tage lang das vor der amerikanischen Atlantik-Küste in $900 \mathrm{~m}$ Tiefe liegende Blake Plateau erforschte und dabei größere Vorkommen an Manganoxyd und Phosphat entdeckte ${ }^{26}$. Abschließend seien in diesem Zusammenhang noch die von der amerikanischen Firma Westinghouse entwickelten Unterwasserfahrzeuge der Serie "Deepstar" genannt, die in Tiefen bis zu 1200, 3600 und $6000 \mathrm{~m}$ operieren sollen ${ }^{27}$.

Von der Tauchkugel und dem Bathyscaph unterscheidet sich keines der genannten Fahrzeuge insofern, als hier wie dort der in großen Tiefen auftretende Wasserdruck durch einen Druckkörper abgefangen wird und in ihrem Innern im wesentlichen die gleichen Lebensbedingungen aufrechterhalten werden wie oberhalb der Meeresoberfläche. Etwas grundlegend Neues stellen demgegenüber die Forschungsvorhaben dar, in welchen der Mensch sich anschickt, für längere Zeit in Unterwasser-Stationen auf dem Meeresboden zu leben, zu arbeiten und sich durch Anpassung an die Druckverhältnisse in der Tiefe in die Lage zu versetzen, diese Gebilde sogar zu verlassen. Daß der Mensch ohne Anpassung an diese

22 Die wissenschaftliche Bedeutung ihrer Fahrt läßt sich am besten daraus ersehen, daß eines der Forschungsprogramme des Internationalen Geophysikalischen Jahres 1958 darin bestand, die Messungen der "Meteor ${ }^{\star}$ zu wiederholen; vgl. Cromie, a. a. O., S. $80 \mathrm{ff}$.

$23 \mathrm{Als}$ Vorläufer dieser Fahrzeuge ist die von Jacques-Yves Cousteau konstruierte "Diving Saucer" zu nennen. Dieses speziell für die Erforschung des Festlandsockels entwickelte Kleinst-U-Boot kann bis etwa $300 \mathrm{~m}$ tauchen und hat schon hunderte von Tauchfahrten durchgeführt; vgl. Coombs, Charles: Deep-Sea World, New York 1966, S. $111 \mathrm{ff}$.

$24 \mathrm{Vgl}$. Soule, a. a. O., S. $11 \mathrm{ff}$.

25 Vgl. Soule, a. a. O., S. 255 .

26 Vgl. Soule, a. a. O., S. $63 \mathrm{ff}$.

27 Vgl. Coombs, a. a. O., S. $118 \mathrm{ff}$. Damit ist nur ein kleiner Teil der laufenden Entwicklungsarbeiten genannt. Einen Überblick über weitere Projekte liefert Soule, a. a. O., S. $18 \mathrm{ff} ., 84 \mathrm{ff}$. 
Druckverhältnisse Wochen und Monate unter der Meeresoberfläche leben kann, haben schon die Fahrten von Atom-U-Booten unter dem Eis des Arktischen Ozeans und um die Welt im getauchten Zustand bewiesen, bei denen auch umfangreiche ozeanographische Forschungsarbeiten durchgeführt wurden ${ }^{28}$. Inzwischen ist es dank der Entwicklung neuer Tieftauch-Systeme möglich geworden, den menschlichen Körper den in größeren Tiefen auftretenden Druckverhältnissen längere Zeit auch direkt auszusetzen ${ }^{29}$. Daher können sich schon heute Taucher in Tiefen bis $\mathrm{zu} 200 \mathrm{~m}$ frei bewegen und dort arbeiten. Für die Zukunft rechnet man sogar damit, daß durch die Verwendung flüssiger Sauerstoffträger der Arbeitsbereich von Tauchern bis auf $500 \mathrm{~m}$ Tiefe und mehr erweitert werden kann ${ }^{30}$. Eine ideale Ausgangsbasis für die Arbeit solcher Tiefseetaucher stellen auf dem Meeresboden installierte Unterwasser-Stationen dar. Bahnbrechende Arbeit bei deren Entwicklung hat der Franzose Jacques-Yves Cousteau geleistet, in dessen "Conshelf I" schon im Jahre 1962 zwei Mann eine Woche lang vor Marseille in $10 \mathrm{~m}$ Tiefe auf dem Boden des Mittelmeeres lebten. Bei einem zweiten Versuch im Jahre 1963 wohnten und arbeiteten mehrere Forscher einen Monat lang in $11 \mathrm{~m}$ Tiefe auf dem Boden des Roten Meeres, zwei von ihnen eine Woche lang in $27 \mathrm{~m}$ Tiefe ${ }^{31}$. Und schon zwei Jahre später hielten sich während des Unternehmens "Conshelf III“ sechs Mann drei Wochen lang sogar in fast $100 \mathrm{~m}$ Tiefe auf ${ }^{32}$. Die amerikanische Marine führte im Jahre 1964 das Unternehmen „Sealab I“ durch, bei dem vier Taucher elf Tage lang in $57 \mathrm{~m}$ Tiefe vor den Bermudas auf dem Boden des Atlantiks lebten, und im Jahre 1965 vor der kalifornischen Küste in $62 \mathrm{~m}$ Tiefe das Unternehmen „Sealab II“, bei dem der schon als Astronaut bekannt gewordene M. Scott Carpenter dreißig Tage unter Wasser wohnte und arbeitete ${ }^{33}$. Das Unternehmen "Sealab III“, welches vorsah, daß fünf Mann je zwölf Tage vor San Diego in Kalifornien $185 \mathrm{~m}$ unter dem Meeresspiegel leben sollten, wurde unlängst nach einem Todesfall auf unbestimmte Zeit unterbrochen ${ }^{34}$. Auch in der Bundesrepublik ist eine Unterwasser-Station, die drei Wissenschaftler beherbergen kann, gebaut und im vorigen Jahr erfolgreich in der Flensburger Förde erprobt worden. Sie soll vor allem der Durchführung meeresbiologischer Untersuchungen dienen ${ }^{35}$.

Abschließend ist auf Projekte hinzuweisen, die vielleicht für die praktische Nutzung des Meeresbodens und -untergrundes einmal die größte Bedeutung erlangen werden, nämlich die Entwicklung sogenannter General Purpose Submersibles (GPS). Hierbei handelt es sich um Gebilde, die die Eigenschaften der genannten Forschungsunterseeboote und der Unterwasser-Stationen in sich vereinen. Mit ihnen wird es also möglich sein, zu einer beliebigen Stelle des Meeresbodens hinabzutauchen, auf dem Meeresboden niederzugehen und gegebenenfalls das GPS zu verlassen, um Arbeiten außerhalb durchzuführen ${ }^{36}$. Wie schon ihr Name

\footnotetext{
$28 \mathrm{Vgl}$. Soule, a. a. O., S. $119 \mathrm{ff}$.

29 Diese vermeiden den bei der bisher üblichen Verwendung von Druckluft auftretenden Stickstoff-Rausch durch Verwendung eines Gemisches aus Sauerstoff und Helium als Atemluft. Eine Kombination von Tauchglocke und Dekompressionskammern verlängert die für die Arbeit in der Tiefe zur Verfügung stehende Zeit; vgl. Der Spiegel, Bd. 22 (1968), Nr. 38, S. 85.

30 Vgl. Hersh, a. a. O., S. 9, 21.

31 Hierbei wurden auch mit dem Forschungsunterseeboot „Denise“, welches später erfolgreich bei der Erforschung des kalifornischen Festlandsockels eingesetzt wurde, direkt von der Unterwasser-Station aus Tauchfahrten in deren Umgebung unternommen; vgl. Soule, a. a. O., S. 152, $38 \mathrm{ff}$.

32 Vgl. Soule, a. a. O., S. 165.

33 Zum Unternehmen Sealab I und II vgl. Coombs, a. a. O., S. $218 \mathrm{ff}$.; Soule, a. a. O., S. $151 \mathrm{ff}$.

34 Vgl. Die Welt vom 18. und 19. 2. 1969. Danach läuft gegenwärtig vor den Virgin Islands in $13 \mathrm{~m} T$ Tiefe das Unternehmen Tektite.

35 Vgl. Der Spiegel, Bd. 22 (1968), Nr. 39, S. 54.

36 Vgl. Soule, a. a. O., S. $167 \mathrm{ff}$.
} 
andeutet, werden die GPS so vielseitig verwendbar sein, daß man mit ihnen von der Überwachung, Instandhaltung und Reparatur unterseeischer Bohrstellen und Pipelines ${ }^{37}$ bis hin zur Versorgung bemannter Unterwasser-Stationen alle erforderlichen Arbeiten durchführen kann.

Die Ergebnisse der bereits durchgeführten Forschungsvorhaben deuten darauf hin, $\mathrm{da} ß$ es an der Gelegenheit für solche praktischen Arbeiten in der Zukunft nicht fehlen wird; denn sie haben schon jetzt die Vorstellungen über die Tiefe der Ozeane grundlegend gewandelt. So wußte man zum Beispiel, als die "Challenger“ auslief, noch nicht einmal, daß sich die Festlandmassen vielfach größere Strekken - bis zu mehreren hundert Seemeilen ${ }^{38}$ - in verhältnismäßig geringer Tiefe unter dem Meer fortsetzen und geologisch mit diesem sogenannten Festlandsockel eine Einheit bilden ${ }^{39}$. Heute ist das erst im Jahre 1887 entdeckte Phänomen des Festlandsockels ${ }^{40}$ so intensiv erforscht, daß man wesentlich bessere Kenntnisse über die in ihm verborgenen Naturschätze besitzt und sie auch schon in großem Umfang nutzt. Das gilt besonders für Erdöl und Erdgas. Schon jetzt kommen 11 Prozent der Erdöl- und 6 Prozent der Erdgasproduktion der Welt aus dem Festlandsockel von nur 18 Staaten. Im Festlandsockel von mindestens 60 Staaten wird nach Erdöl gebohrt oder die Förderung vorbereitet ${ }^{41}$. In zehn Jahren wird der Festlandsockel nach jüngsten Schätzungen sogar schon 40 Prozent der Welt-Erdölproduktion liefern ${ }^{42}$. Daß diese Zahl nicht zu hoch gegriffen ist, lassen einige Erdölfunde neueren Datums vermuten. So wurden im arktischen Festlandsockel der Sowjetunion derart große Vorkommen entdeckt, daß der russische Festlandsockel schon im Jahre 1980 wahrscheinlich ebensoviel Erdöl liefern wird wie die gesamte übrige Sowjetunion ${ }^{43}$. Ahnliche Bedeutung haben die im Jahre 1967 in Alaska entdeckten Erdölvorkommen, die sich vermutlich nach Kanada und unter der Beaufort-See fortsetzen ${ }^{44}$.

$\mathrm{Da}$ allein in dem zu Alaska gehörenden Teil des Feldes mehr Erdöl vermutet wird als in ganz Texas, das bisher den größten Anteil an der Erdölproduktion der Vereinigten Staaten hatte, dürften diese Vorkommen die Vereinigten Staaten zum größten Erdölproduzenten der Welt neben Kuwait aufsteigen lassen. Die Funde in Alaska liefern gleichzeitig ein gutes Beispiel dafür, wie kurz die Zeitspanne zwischen Erforschung und Ausbeutung heute geworden ist. Trotz denkbar ungünstiger klimatischer Bedingungen und ausgesprochen schlechter Verkehrsverbindungen ist auf dem Festlandteil des Erdölfeldes bereits die Produktion aufgenommen worden, obwohl die Bohrungen erst ein Jahr zuvor pfündig geworden sind ${ }^{45}$. Von den Erdgasfunden sind vor allem die im Festlandsockel der Nordsee und im Golf von Mexico zu nennen. Die Erdgasförderung aus dem britischen Teil des Festlandsockels der Nordsee soll schon im Oktober dieses Jahres aufgenommen werden und nach einer Anlaufzeit die Hälfte des gegen-

37 Zur Zeit wird vor der Küste Louisianas auf dem Meeresboden ein Rohrleitungsnetz von 1600 km Länge zur Ausbeutung eines unterseeischen Erdgasfeldes installiert; vgl. Time (Atlantic Edition) vom 8. 11. 1968, S. 70 .

38 Vgl. u. a. die Angaben bei Mouton, M. W.: The Continental Shelf, Den Haag 1952, S. $22 \mathrm{ff}$

39 Vgl. Cromie, a. a. O., S. $42 \mathrm{ff}$.

40 Nad, Kunz, Josef L.: Festlandsockel, in: Strupp-Schlochauer: Wörterbuch des Völkerrechts, 2. Aufl., Bd. 1, Berlin 1960, S. 516-520.

41 Vgl. Young, Richard: The Legal Regime of the Deep-Sea Floor, in: The American Journal of International Law, Bd. 62 (1968), S. 641-653 (641, Anm. 2). Im folgenden zitiert als Regime. Nach Keil a. a. O., S. 2177, werden sogar schon 16 Prozent der Welt-Erdölproduktion aus dem Festlandsockel gewonnen.

42 So Pardo-Gauci: The Sea Bed: Common Heritage of Mankind, in: War'Peace Report, Bd. 8 (1969), Nr. 7 , S. 3-6 (4). Nach Keil, a. a. O., S. 2177, werden es nur 33 Prozent sein.

43 Vgl. Pardo-Gauci, a. a. O., S. 4

44 Vgl. Der Spiegel, Bd. 22 (1968), Nr. 48, S. 178-180.

45 Vgl. Time (Atlantic Edition) vom 13. 12. 1968, S. 64-65. 
wärtigen Stadtgasverbrauches Großbritanniens decken ${ }^{46}$. Vor der Küste Louisianas hat man in einer Wassertiefe von $180 \mathrm{~m}$ mit der Ausbeutung eines Erdgasfeldes begonnen, welches sogar ein Viertel der gesamten Erdgasvorkommen der Vereinigten Staaten enthalten soll ${ }^{47}$.

Die Funde beschränken sich jedoch nicht nur auf Erdöl und Erdgas. In Japan wird vom Boden der Bucht von Tokio hochwertiges Eisenerz gefördert ${ }^{48}$. Vor der Küste Malaysias wird Zinn abgebaut und vor den Küsten Alaskas und der Südafrikanischen Union sogar Gold und Platin ${ }^{49}$. Reiche Goldvorkommen sind auch vor der südamerikanischen Pazifik-Küste entdeckt worden ${ }^{50}$. Die im Meeresboden und -untergrund entdeckten Schwefellager sind so groß, daß schon jetzt die Welt-Schwefelproduktion zum größten Teil von dort kommt ${ }^{51}$. Auch Phosphate werden ebenfalls bereits aus dem Meeresboden gewonnen ${ }^{51}$. Der mehr als die Hälfte des Meeresbodens bedeckende Schlamm besteht zu 95 Prozent aus dem für die Zementerzeugung benötigten Kalziumkarbonat ${ }^{52}$. Eine noch größere Bedeutung wird den schon von der "Challenger" entdeckten Metallablagerungen auf dem Boden der Tiefsee vorhergesagt. Diese liegen in knollenförmigen Gebilden - sogenannten nodules - wie eine Art Geröll lose über riesige Teile des Tiefsee-Bodens verstreut. Normalerweise haben sie Kartoffelgröße und enthalten 20 Prozent Mangan und je 0,5 Prozent Nickel, Kobalt und Kupfer sowie 15 Prozent Eisen, das jedoch in diesem Zusammenhang von untergeordneter Bedeutung ist ${ }^{53}$. Eines der Felder im Pazifik, welches erst im Internationalen Geophysikalischen Jahr entdeckt, wurde, ist mit nodules bedeckt, die sogar 50 Prozent Mangan und je 2 Prozent Kobalt, Kupfer und Nickel enthalten ${ }^{54}$. In welchen Mengen diese nodules auf dem Boden der Tiefsee vorhanden sind, veranschaulicht am besten der in rund $600 \mathrm{~km}$ Entfernung von der amerikanischen Westküste verlaufende Gürtel aus Mangan-nodules. Auf einer Fläche von der achtfachen Größe des Staates Texas liegen dort nodules in einer Dichte von über 50 Pfund pro $\mathrm{qm}$. Eine wesentlich geringere Dichte soll nach Ansicht von Fachleuten bereits eine wirtschaftliche Ausbeutung ermöglichen ${ }^{55}$. Lediglich die große Tiefe, in der vor allem die nodules mit höherem Metallgehalt anzutreffen sind, verhindert bisher ihre Ausbeutung. Es bestehen allerdings bereits Pläne, den Boden der Tiefsee mit einer Art überdimensionalem Saugbagger nach den wertvollen nodules abzusaugen ${ }^{56}$. Auch andere Möglichkeiten ihres Abbaues sind denkbar. Man kann daher davon ausgehen, daß die Techniken für eine wirtschaftliche Nutzung dieser Vorkommen bald entwickelt sein werden ${ }^{57}$. Für die fernere Zukunft würden sich noch sehr viel bessere Nutzungsmöglichkeiten eröffnen, wenn es gelänge, die Bedingungen für die Entstehung der nodules zu klären. Man könnte dann nämlich versuchen, den Entstehungsprozeß künstlich nachzuahmen und die nodules in flacheren Gewässern industriell zu züchten. Solche "Metall-Farmen" auf dem Meeresboden könnten eines Tages auch das seltene Vanadium, welches unter anderem für die Produktion von Edelstählen

46 Nach Survey of British and Commonwealth Affairs, Bd. 2 (1968), S. 790-791; vgl. auch Keesing's Contemporary Archives 1968, S. 22973-22974

47 Vgl. Time (Atlantic Edition) vom 8. 11. 1968, S. 70

48 Vgl. Coombs, a. a. O., S. 170.

49 Vgl. Pardo-Gauci, a. a. O., S. 3.

50 Vgl. Frankfurter Allgemeine Zeitung vom 19. 2. 1969.

51 Vgl. Keil, a. a. O., S. 2177.

52 Vgl. Stewart, Harris B., Jr.: Deep Challenge, Toronto/New York/London 1966, S. 161.

53 Vgl. Cowen, a. a. O., S. $263 \mathrm{ff}$.

54 Vgl. Stewart, a. a. O., S. $153 \mathrm{ff}$

55 Vgl. Stewart, a. a. O., S. 153 romie, a. a. O., S. 256.

56 Vgl. Cowen, a. a. O., S. $265 \mathrm{ff}$

57 Zum gegenwärtigen Stand vgl. Pardo, Arvid: Who will control the Seabed, in: Foreign Affairs, Bd. 47 (1968), S. $123-137$ (123 ff.). Im folgenden zitiert als Seabed. 
benötigt wird, oder Kupfer erzeugen ${ }^{58}$. Da die Flüsse der Erde den Weltmeeren ständig neue Mineralien in gelöstem Zustande zuführen, kann auch eine intensive Ausbeutung dieser Naturschätze kaum zur Erschöpfung der Vorräte führen ${ }^{59}$. Damit ist ein wesentlicher Unterschied angesprochen, der zwischen der Ausbeutung von Naturschätzen auf dem Lande und auf dem Meeresboden besteht und die Nutzung des Bodens und Untergrundes der Tiefsee so zukunftsträchtig erscheinen läßt ${ }^{60}$ :

„Taking minerals from the land in like living on one's savings. But mining the ocean is living on income."

Am Schluß des Überblicks über die bisherige Entwicklung und die sich abzeichnenden Möglichkeiten einer friedlichen Nutzung des Bodens und Untergrundes der Tiefsee soll aber nicht verschwiegen werden, daß sie ebenso wie die Ausbeutung der Naturschätze des Festlandsockels auch ihre Schattenseiten haben wird. Im Bereich des Festlandsockels haben zum Beispiel an einigen Stellen des Golfes von Mexico Bohrinseln sogar schon zu einer Beeinträchtigung der Schifffahrt geführt ${ }^{61}$. Die Erdölförderung im Bereich des Festlandsockels verursachte bereits erhebliche Ölverschmutzungen ${ }^{62}$. Dementsprechend wird man auch nicht fehlgehen in der Annahme, daß ein gewisses $M a ß$ an Meeresverschmutzung bei der Nutzung des Bodens und Untergrundes der Tiefsee in bestimmten Gebieten auf die Dauer ebenfalls unvermeidbar sein wird. Die Rückwirkungen solcher Verunreinigungen auf die Meeresfauna und -flora dürfen allerdings nicht unterschätzt werden. Vor allem könnten sie verheerende Folgen für den Fischreichtum der Ozeane haben, welcher für die Protein-Versorgung der Bevölkerung in der ganzen Welt zunehmend an Bedeutung gewinnt ${ }^{63}$. Auch ist in diesem Zusammenhang darauf hinzuweisen, daß das Meerwasser selbst in immer größeren Mengen insbesondere zur Deckung des Trinkwasserbedarfs herangezogen wird ${ }^{64}$. Verschmutzungen größeren Umfangs können daher die Trinkwasser-Versorgung ebenfalls gefährden. Allgemein ausgedrückt, birgt also die Nutzung des Bodens und Untergrundes der Tiefsee die Gefahr in sich, daß andere Formen der Nutzung der Weltmeere beeinträchtigt werden und dadurch neuer Konfliktstoff zwischen den Staaten entsteht. Wie notwendig es ist, sich beizeiten mit der Bewältigung der hiermit zusammenhängenden rechtlichen Probleme zu befassen, zeigt die jüngste Entwicklung in der Tankschiffahrt. Dort führte der Bau immer größere Einheiten bei Tankerunfällen zu Ölverschmutzungen, deren Ausmaß noch wenige Jahre zuvor einfach unvorstellbar war'55. Ahnliche Probleme ergeben sich schon heute aus einer anderen Form der Nutzung des Bodens der Tiefsee, nämlich der Versenkung von radioaktivem Müll und giftigen Industrieabfällen an einigen Stellen der Weltmeere ${ }^{66}$. Schließlich soll auf einen weiteren uner-

58 Diese Form der Metallproduktion wird sich wahrscheinlich den Umstand zunutzemachen, daß einige im Wasser lebenden Organismen die Eigenschaft besitzen, bestimmte Metalle in ungewöhnlich hohen Konzentrationen in ihrem Körper anzusammeln; vgl. Stewart, a. a. O., S. $159 \mathrm{ff}$.

59 In diesem Zusammenhang ist es vielleicht von Interesse, daß bereits die gesamte Magnesium-Produktion und ein Teil der Brom-Erzeugung der Vereinigten Staaten aus dem Meerwasser gewonnen wird; vgl. Cromie, a. a. O., S. 259.

60 Cowen, a. a. O., S. 259.

61 Vgl. Swirin, a. a. O., S. 7.

62 Vor der kalifornischen Küste sind bereits so starke Verschmutzungen aufgetreten, daß dort weitere Bohrungen untersagt wurden; vgl. Die Welt vom 8. 2. 1969.

63 Vgl. Keil, a. a. O., S. 2177.

$64 \mathrm{Vgl}$. Coombs, a. a. O., S. $178 \mathrm{ff}$.

$65 \mathrm{Zu}$ den hiermit verbundenen rechtlichen Problemen vgl. demnächst Böhme, Eckart: Der "Torrey Canyon“Fall, Hamburg 1969.

66 In der nächsten Zeit wollen allein die fünf Staaten Belgien, Bundesrepublik Deutschland, Frankreich, Großbritannien und die Niederlande auf dem Boden des Atlantischen Ozeans 11000 Tonnen radioaktiver Abfälle deponieren; vgl. Rousseau, Charles: Chronique des faits internationaux, in: Revue générale de droit international public, Bd. 72 (1968), S. 753-754. 
wünschten Nebeneffekt hingewiesen werden, der bei der Ausbeutung der Naturschätze des Bodens und Untergrundes der Tiefsee eintreten könnte, nämlich die Gefahr einer Störung bestimmter Weltrohstoffmärkte. Nach neueren Schätzungen wird es in zwanzig Jahren möglich sein, etwa 70 Prozent des Weltverbrauchs an Nickel, Kupfer, Kobalt und Mangan aus dem Boden der Tiefsee zu decken ${ }^{67}$. Da hierdurch das Angebot an diesen Rohstoffen beträchtlich steigen würde, schätzt man, daß ihr Weltmarktpreis zum Teil um 10 bis 50 Prozent gesenkt werden könnte ${ }^{68}$. Die Folgen einer solchen Preissenkung für die jetzigen Haupterzeugerländer könnten sehr schwerwiegend sein. Andererseits wird ohne die Ausbeutung dieser Vorkommen bald eine spürbare Verknappung dieser Rohstoffe eintreten, da ihr Verbrauch ständig steigt und die Vorkommen auf dem Festland begrenzt sind. Für Industrienationen ohne ausreichende Rohstoffbasis wie etwa die Bundesrepublik Deutschland bietet also eine intensivere Beschäftigung mit den Möglichkeiten der Nutzung des Bodens und Untergrundes der Tiefsee die einmalige Chance, die bei einer fortschreitenden Verknappung wichtiger Rohstoffe immer bedenklicher werdende Abhängigkeit von Lieferungen aus dem Ausland auf bestimmten Sektoren zu verringern, wenn nicht sogar gänzlich zu beseitigen ${ }^{69}$. Obwohl die Bundesrepublik nicht Mitglied der Vereinten Nationen ist, in deren Gremien die mit der Nutzung des Bodens und Untergrundes der Tiefsee zusammenhängenden Fragen gegenwärtig erörtert werden, dürfte es dazu zweckmäßig sein, daß sie sich in geeigneter Form in den dort stattfindenden Meinungsbildungsprozeß einschaltet. Hierbei könnte es nicht schaden, wenn die bei uns im Gange befindliche Diskussion dieser Fragen mehr als bisher in der Ơffentlichkeit ausgetragen wird, damit man im Ausland sieht, daß auch hier die Bereitschaft vorhanden ist, an der Lösung der Probleme mitzuarbeiten.

Das erscheint um so notwendiger, als die sich abzeichnenden Möglichkeiten einer militärischen Nutzung der in Frage stehenden unterseeischen Gebiete ebenfalls lebenswichtige Interessen der Bundesrepublik im Kriegsfalle berühren. Bisher wurde der Seekrieg nämlich vorwiegend an der Meeresoberfläche oder in verhältnismäßig geringer Tiefe darunter, also im wesentlichen zweidimensional geführt, und die militärische Nutzung des Meeresbodens bestand vor allem in der Verankerung von Minen und U-Boot-Netzen in verhältnismäßig flachen Gewässern. Die technische Entwicklung der Gegenwart dagegen eröffnet dem Seekrieg in der Tiefe der Ozeane eine dritte Dimension und verändert dadurch die strategischen Gegebenheiten grundlegend ${ }^{70}$. Dementsprechend hat sich mit fortschreitender Vergrößerung der Tauchtiefen und Verlängerung der Tauchzeiten auch größerer Einheiten, welche erst die Verwendung der Kernenergie ermöglichte, die Aktivität der Marinen zu einem bedeutenden Teil unter die Wasseroberfläche verlagert. Das beruht einmal auf der Erwägung, daß Kriegsschiffe, die in größeren Tiefen operieren, weitgehend den Einwirkungsmöglichkeiten aus der Luft entzogen sind. Zum anderen ist es auch leichter, die jeweilige Position solcher Einheiten geheim zu halten. Besonders für Einheiten wie die mit interkontinentalen Raketen ausgerüsteten Polaris-U-Boote ist das sehr wich-

67 Nach Reilly, Pat: The Politics of the Ocean Bottom, in: War/Peace Report, Bd. 8 (1968), Nr. 7, S. 6-7. $68 \mathrm{Vgl}$. Levy, a. a. O., S. 141.

69 Wie die jüngst erstellte Studie des Bundeswirtschaftsministeriums über die Rohstoffversorgung der westdeutschen Industrie zeigt, droht von dieser Abhängigkeit auf die Dauer eine Verschlechterung der Wettbewerbsposition der Bundesrepublik auf dem Weltmarkt; vgl. Der Spiegel, Bd. 23 (1969), Nr. 5, S. 38-40.

70 Nach Admiral David L. McDonald erweitert nach dem heutigen Stande der Technik jede Vergrößerung der Tauchtiefe von U-Booten um $30 \mathrm{~m}$ deren Operationsraum um rund 10 Millionen km; ; vgl. Hersh, a. a. O., S. 8 . 
tig, da deren Abschreckungswirkung zum Teil darauf beruht, daß sie in der Tiefe der Ozeane vor Überraschungsangriffen verborgen sind und ihre Raketen auch nach einem solchen Angriff zu einem atomaren Gegenschlag verwendet werden können. Bei dem gegenwärtigen Stand der Technik müssen jedoch auch AtomU-Boote von Zeit zu Zeit zu Versorgungszwecken und zur Durchführung von Reparaturen Häfen anlaufen oder wenigstens auftauchen. Geheimhaltung und Abschreckung sind daher erst vollkommen, wenn solche Einheiten von Stützpunkten aus operieren können, die ebenfalls unter der Meeresoberfläche liegen. Aus diesen und weiteren Erwägungen interessieren sich die Marineführungen zunehmend auch für den Boden der Tiefsee. In den Vereinigten Staaten soll sogar schon an der Entwicklung einer neuen Generation von Atom-U-Booten gearbeitet werden, die von Stützpunkten am Meeresboden aus operieren können ${ }^{71}$.

Eine nähere Beschäftigung mit den militärischen Zwecken dienenden ozeanographischen Forschungsprogrammen läßt allerdings darauf schließen, daß unterseeische U-Boot-Stützpunkte nur ein Teilaspekt einer sehr viel weitergehenden Entwicklung sind. Das ist allein schon wegen des enormen Aufwandes an personellen und sachlichen Mitteln anzunehmen, der auf diesem Gebiet besonders von den Großmächten getrieben wird. Die amerikanische Marine zum Beispiel beschäftigt mehr als 1000 Wissenschaftler und Ingenieure allein auf diesem Sektor ${ }^{72}$. Von den 300 Forschungsschiffen der Sowjetunion und den 1500 dort auf diesem Gebiet tätigen Ozeanographen ${ }^{73}$ dürfte ebenfalls ein großer Teil im Bereich militärischer Forschung eingesetzt sein. Konkrete Angaben über die in der Sowjetunion für rein militärische Meeresforschung aufgewandten Mittel waren nicht zu erlangen. In den Vereinigten Staaten dagegen verschafft bereits das Studium der Haushaltspläne interessante Aufschlüsse. Dort entfielen von den 462,3 Millionen Dollar, die im Voranschlag für das Haushaltsjahr 1968 insgesamt für Meeresforschung und -technik vorgesehen waren, allein 258,7 Millionen Dollar - also mehr als die Hälfte - auf militärische Projekte ${ }^{74}$. Die Aufteilung dieses Betrages auf die einzelnen Vorhaben veranschaulicht besser als alle theoretischen Erwägungen, mit welchen Arten militärischer Nutzung des Bodens und Untergrundes der Tiefsee in Zukunft zu rechnen ist.

Als zur Zeit wichtigstes Forschungsprogramm ist das sogenannte Deep Submergence Systems Project (DSSP) anzusehen, für das im Jahre 1968 der Riesenbetrag von 72,2 Millionen Dollar, d. h. fast ein Drittel der gesamten militärischen Ausgaben in diesem Bereich, bestimmt war ${ }^{74}$. Das Projekt hat offiziell mit besonderer Dringlichkeit die Entwicklung von Fahrzeugen und Techniken zum Gegenstand, mit deren Hilfe die Besatzungen havarierter Unterseeboote gerettet werden können ${ }^{75}$. Und zwar ist in diesem Rahmen unter anderem vorgesehen, bis zum Jahre 1972 die Auffindung und Bergung kleiner Gegenstände aus Tiefen bis zu $6000 \mathrm{~m}$ und großer Objekte aus Tiefen bis etwa $250 \mathrm{~m} \mathrm{zu}$ ermöglichen ${ }^{76}$. Das Programm hat jedoch eine erheblich größere Bedeutung, da man mit den gleichen Fahrzeugen und Techniken auch militärische Einrichtungen auf dem Boden der Tiefsee wie zum Beispiel Treibstoff-, Munitions- und sonstige

71 Vgl. Der Spiegel, Bd. 22 (1968), Nr. 40, S. 198-200.

72 Vgl. Hersh, a. a. O., S. 9.

73 Vgl. Pardo-Gauci, a. a. O., S. 3.

74 Vgl. Technology Week vom 30.1. 1967, S. 28

75 Vgl. Hersh, a. a. O., S. 9.

76 Vgl. Niblock, Robert W.: Marine Council Evaluating Special Projects, in: Technology Week vom 12.6. 1967, S. $37-39$. 
Nachschublager, Warn- und Úberwachungssysteme der verschiedensten Art und sogar Raketenabschußbasen 77 inspizieren, versorgen und instandhalten könnte.

Weitere 4 Millionen Dollar waren im Haushaltsvoranschlag 1968 für das Deep Ocean Technology (DOT) Programm vorgesehen, welches sich noch in der Anlaufphase befindet ${ }^{78}$. Die vorerst vergleichsweise geringen Ausgaben dürfen nicht darüber hinwegtäuschen, daß es sich hierbei ebenfalls um ein Schlüsselprojekt handelt, welches in seiner Bedeutung dem DSSP nicht nachsteht. Denn es geht dabei um nichts weniger als die Inbesitznahme und Nutzung der Tiefsee ${ }^{79}$. Und zwar ist hiermit vor allem der Boden und Untergrund der Tiefsee gemeint. Das kann man den Verlautbarungen von offizieller Seite entnehmen, im Rahmen des DOT-Programmes solle der gesamte Fragenkomplex untersucht werden, der sich aus der Installation von Einrichtungen auf dem Boden der Tiefsee ergäbe ${ }^{79}$. Welche Fülle von verschiedenartigen militärischen Einrichtungen auf dem Boden der Tiefsee denkbar ist, wurde bereits angedeutet. Dementsprechend wird als Ziel des Projekts die Lösung so mannigfaltiger Aufgaben wie die Entwicklung und Erprobung neuer Werkstoffe $e^{80}$, Antriebsaggregate, Kommunikationsmittel und Navigationshilfen sowie die Bewältigung all der Probleme genannt, die mit dem sogenannten "sea floor engineering“ verbunden sind ${ }^{81}$. Hinter dieser auf den ersten Blick nichtssagenden Bezeichnung verbirgt sich weitaus mehr als die Installation militärischer Einrichtungen auf dem Boden der Tiefsee. Das wird deutlich, wenn man sich überlegt, welche Rüclswirkungen die Existenz solcher Einrichtungen ihrerseits auf die Seekriegsführung haben würde. Sind nämlich erst einmal auf dem Boden der Tiefsee Überwachungssysteme installiert, mit denen man die Fahrtrouten von unter Wasser operierenden Einheiten verfolgen kann, dann sind zum Beispiel auch die Polaris-U-Boote nicht mehr in der Tiefe der Ozeane verborgen, sondern dort fast genauso ungeschützt wie an der Meeresoberfläche. Damit hätten sie ein Großteil ihrer strategischen Bedeutung eingebüßt. Etwas anderes würde jedoch für unbemannte Raketensilos und andere weitgehend automatisierte Einrichtungen, aber auch für bemannte Unterwasser-Stützpunkte gelten, die tief in den Untergrund der Tiefsee eingelassen werden und daher selbst bei Entdeckung nur schwer zu zerstören sind ${ }^{82}$. Es ist deshalb anzunehmen, daß sich das DOT-Projekt auch mit den Techniken befaßt, die zur Installation solcher befestigten Einrichtungen erforderlich sind.

Schließlich ist das bereits erwähnte „Sealab“-Unternehmen zu nennen. Es gehört zwar organisatorisch zum DSSP83, ist aber insofern besonderer Erwähnung wert, als es bereits jetzt praktische militärische Bedeutung hat. Mit den bei diesem Unternehmen verwendeten Unterwasser-Laboratorien kann man nämlich genausogut strategisch wichtige Punkte des Tiefsee-Bodens wie etwa die Gipfel bestimmter unterseeischer Gebirgszüge ständig durch bemannte Unterwasser-

77 Solchen Abschußbasen käme vor allem deshalb große Bedeutung zu, weil nicht nur ihr Standort leichter als auf dem Lande geheimgehalten werden kann, sondern auch weil dort installierte Antiraketen-Systeme gegnerische interkontinentale Raketen schon weit vor dem eigenen Territorium und vor Abtrennung der Sprengköpfe abfangen können.

78 Vgl. Niblock, a. a. O., S. 37

79 Vgl. Hersh, a. a. O., S. 9.

80 Bemerkenswerterweise erweist sich Glas für die Verwendung in großen Tiefen als besonders geeignet; vgl. Wilks, Willard E.: Navy Trying Radio to avoid Submersible Hull Penetration, in: Aerospace Technology vom 12. 2. 1968 , S. 52-54.

81 Vgl. Hersh, a. a. O., S. 9.

82 In diesem Zusammenhang ist darauf hinzuweisen, daß unterseeische Einrichtungen am besten in felsigem Grund installiert werden können und etwa 20 Prozent des Tiefsee-Bodens aus Fels besteht sowie bei 40 Prozent die darüber liegenden ungeeigneten Bodenschichten nicht sehr mächtig sind; vgl. Hersh,

83 Vgl. Hersh, a. a. O., S. 9. 
Stützpunkte besetzt halten ${ }^{84}$. Zur Veranschaulichung der weitreichenden Konsequenzen dieser schon mit den heutigen technischen Mitteln zu realisierenden Möglichkeit, den Boden der Tiefsee militärisch zu nutzen, möge folgendes Beispiel genügen: Ein Staat, der bestimmte Erhebungen im Mittelatlantischen Rükken besetzen würde, könnte von hier aus im Falle eines Krieges wirksamer als je zuvor die Hauptschiffahrtswege über den Atlantik kontrollieren und so die europäischen Partner des NATO-Bündnisses von ihren überseeischen Zufuhren abschneiden. Solche Erhebungen finden sich auch an anderen Stellen der Weltmeere. Hinsichtlich einiger Punkte im Pazifik werden sogar schon öffentlich Gedanken geäußert, die sie in strategische Überlegungen zur Schaffung eines Gegengewichts gegen das asiatische Festland einbeziehen ${ }^{85}$. Das Sealab-Unternehmen bezeichnet also einen kritischen Punkt der Entwicklung. Von nun an besteht nämlich ständig die Gefahr, daß die Möglichkeiten einer militärischen Nutzung des Bodens und Untergrundes der Tiefsee einen verhängnisvollen Wettlauf zur Besetzung strategisch wichtiger Erhebungen des Tiefsee-Bodens auslösen.

II.

Unter diesen Umständen verwundert es nicht, daß der Vorschlag Maltas vom 17. August 1967 so starke Beachtung fand ${ }^{86}$, in die Tagesordnung der 22. Sitzungsperiode der UN-Vollversammlung den Punkt: „Declaration and Treaty Concerning the Reservation Exclusively for Peaceful Purposes of the Sea-Bed and of the Ocean Floor, Underlying the Seas Beyond the Limits of Present National Jurisdiction, and the Use of their Resources in the Interests of Mankind" aufzunehmen ${ }^{87}$. Der Zeitpunkt für diesen Vorstoß war insofern gut gewählt, als einerseits die geschilderte Entwicklung noch nicht soweit fortgeschritten ist, daß der Boden und Untergrund der Tiefsee bereits in nennenswertem Umfang für militärische ${ }^{88}$ oder friedliche $Z$ wecke genutzt werden würde und daraus erwachsene konkrete Streitigkeiten $\mathrm{zu}$ einer Verhärtung der Standpunkte hätten führen können. Andererseits mehren sich die Voraussagen, daß schon in den siebziger Jahren die Nutzung dieser Gebiete - ausgehend von der Ausbeutung der Naturschätze des Kontinentalabfalls - in größerem Stil beginnen werde ${ }^{89}$. Dementsprechend setzt sich allgemein die Erkenntnis durch, daß die Lösung der hiermit zusammenhängenden Fragen rechtlicher, wirtschaftlicher und politischer Art nicht lediglich von akademischem Interesse ist. Hinzu kommt, daß die am 10. Juni 1964 in $\mathrm{Kraft}^{90}$ getretene Genfer Konvention über den Festlandsockel vom 29. April 1958 gemäß ihrem Art. 13 vom 10. Juni dieses Jahres an einer Revision unterzogen werden kann. Damit besteht die Möglichkeit, eine der schwierigsten Fragen, nämlich die Abgrenzung von Festlandsockel und Boden

\footnotetext{
84 Auf die gefährlichen Konsequenzen, die sich ergeben würden, wenn tatsächlich eine der Großmächte solche unterseeischen Stützpunkte errichten würde, hat bereits Pardo hingewiesen; vgl. Address, S. 222. 85 Vgl. Hersh, a. a. O., S. 22. 86 Vgl. o. V.: The U.N.'s Greatest Challenge: The Sea Bed, in: War/Peace Report, Bd. 7 (1967), Nr. 9,

87 Vgl. Verbalnote und Memorandum der Ständigen Mission Maltas bei den Vereinten Nationen, U.N. Doc. A/6695 vom 18. 8. 1967.

88 Nach Pardo sind allerdings schon einige militärische Einrichtungen auf dem Meeresboden außerhalb des Festlandsockels installiert; vgl. Seabed, S. 130.

$89 \mathrm{Vgl}$. den Bericht über die erste internationale Konferenz für Ozeanologie in: Frankfurter Allgemeine Zeitung vom 26. 2. 1969. Hierbei ist damit zu rechnen, daß sich die Entwicklung noch erheblich beschleunigt, falls sich Vermutungen bestätigen sollten, daß auch der Untergrund der Tiefsee größere Erdöl- und.Erdgaslager enthält; vgl. o. V.: Fördersysteme für große Wassertiefen, in: Oel, Bd. 7 (1969), Nr. 1, S. $18-19$

90 Vgl. Ago, Robert: The final Stage of the Codification of International Law, U.N. Doc. A/Cn.4/205/Rev. 1 vom 29. 7. 1968, S. 3. Deutscher Text der Konvention bei Hoog, Günter: Die Genfer Seerechtskonferenzen von 1958 und 1960, Frankfurt am Main/Berlin 1961, S. $111 \mathrm{ff}$.
} 
der Tiefsee, im Rahmen eines bereits bestehenden Vertragswerkes zur Diskussion zu stellen. Die Zeit war also in mehrfacher Hinsicht reif für die Behandlung des Themas.

Auch der Adressat des Vorschlages überraschte nicht; denn die Vereinten Nationen hatten das Thema bereits in anderem Zusammenhang aufgegriffen. Insbesondere beschäftigte sich seit 1966 der Wirtschafts- und Sozialausschuß mit dem wirtschaftlichen Aspekt der Nutzung des Meeresbodens und -untergrundes. Außerdem sind die hiermit angeschnittenen Fragen von so weltweitem Interesse, daß nur in einer Organisation wie den Vereinten Nationen das geeignete Forum für eine erfolgversprechende Diskussion zu erblicken ist. Dementsprechend war in der mit wachsendem Verständnis für die Dringlichkeit einer Lösung schon vorher besonders in den Vereinigten Staaten einsetzenden Diskussion ${ }^{91}$ immer häufiger einer Einschaltung der Vereinten Nationen das Wort geredet worden ${ }^{92}$. Es sind auch bereits detaillierte Vorstellungen über Verfassung und Kompetenzen einer internationalen Organisation zur Verwaltung des Bodens und Untergrundes der Tiefsee entwickelt worden. Diese beziehen die Vereinten Nationen unter Ausschaltung einiger struktureller Mängel, insbesondere des Vetorechts im Sicherheitsrat, zum Teil weitgehend in die Kontrolle des Tiefsee-Bodens ein ${ }^{93}$.

Die von Malta ergriffene Initiative erwies sich aber inhaltlich als zu weitgehend. Regte Malta doch an, unter dem genannten Tagesordnungspunkt konkrete Maßnahmen der Vollversammlung zu beraten, deren Tragweite noch nicht abzusehen ist, nämlich ${ }^{94}$ :

1. Annahme einer Deklaration, die den Boden und Untergrund des Hohen Meeres außerhalb der Grenzen nationaler Jurisdiktion als gemeinsames Erbe der Menschheit erklärt.

2. Feststellung einer begrenzten Zahl allgemeiner Prinzipien hinsichtlich der Erforschung, Erhaltung, Nutzung und Ausbeutung des Meeresbodens und -untergrundes außerhalb nationaler Jurisdiktion.

3. Appell an die Mitgliedstaaten, sich einer weiteren Ausdehnung ihrer Ansprüche auf Hoheitsrechte über den Meeresboden und -untergrund $\mathrm{zu}$ enthalten, bis eine für die Völkergemeinschaft allgemein annehmbare Entscheidung über eine klare Difinition der Unterwasserzonen erzielt ist, über die ein Küstenstaat oder eine Insel solche Rechte ausüben darf.

4. Einsetzung eines Ausschusses zum Entwurf eines Vertrages oder von Verträgen, welche

a) die äußeren Grenzen des unter nationaler Jurisdiktion stehenden Festlandsockels klar festlegen,

b) auf der Grundlage von allgemeinen, durch die Vollversammlung aufgestellten Prinzipien den Rahmen für ein internationales Gesetzbuch über den Meeresboden und -untergrund außerhalb nationaler Jurisdiktion schaffen,

91 In den Vereinigten Staaten kommt das rege Interesse an diesen Fragen nicht von ungefähr; denn dort hat die Entwicklung von Meeresforschung und -technik bereits eine Wachstumsindustrie ersten Ranges entstehen lassen; vgl. Pardo-Gauci, a. a. O.., S. 4. Von der Vielzahl der dort mit diesen Fragen befaßten staatlichen und privaten Organisationen sei in diesem Zusammenhang nur die am 9. 1. 1967 von Präsident L. B. Johnson eingesetzte Commission on Marine Science, Engineering and Recources genannt, die gerade ihren ersten Bericht vorgelegt hat; vgl. International'Herald Tribune vom 14. 1. 1969.

92 Vgl. u. a. Stoessinger, John G.: Financing the United Nations, New York 1961, S. $66 \mathrm{f}$.; EichelbergerChristy: Comments on International Control of the Sea's Resouces, in: Alexander, Lewis M.: The Law of the Sea - Offshore Boundaries and Zones, Columbus 1967, S. 299-309.

$93 \mathrm{Vgl}$. zum Beispiel den Bericht über die Arbeit des Center for the Study of Democratic Institutions in Santa Barbara, Kalifornien, von Reilly, a. a. O.

94 Vgl. auch Pardo, Adress, S. 226. 
c) die Schaffung eines internationalen Organs vorsehen, welches neben der Verwaltung des Meeresbodens und -untergrundes außerhalb nationaler Jurisdiktion auch die Verantwortung für die Förderung und Koordinierung internationaler Maßnahmen im Hinblick auf schwerwiegende Probleme von universellem Interesse, die den Bereich der See als Ganzes betreffen, übernehmen könnte.

Mangelnde Bereitschaft, das Thema der Nutzung des Bodens und Untergrundes der Tiefsee mit einer so weitgehenden Zielsetzung zu erörtern, zeigte sich schon während der Beratungen in dem Allgemeinen Ausschuß der Vollversammlung. Zwar unterstützte der amerikanische Delegierte, Arthur J. Goldberg, den Antrag Maltas in einer bemerkenswert positiven Stellungnahme und setzte sich dafür ein, dem Punkt besondere Dringlichkeit auf der Tagesordnung des (Ersten) Politischen und Sicherheits-Ausschusses zu geben. Vor allem von den Delegierten einiger latein-amerikanischer Staaten wurde aber eine Verweisung an den (Sechsten) Rechts-Ausschuß befürwortet. Erst nachdem auf eine Anregung Maltas vom 6. Oktober 1967 hin das Schwergewicht der Thematik von den rechtlichen Fragen auf die technischen, wirtschaftlichen und sonstigen Vorfragen verlegt wurde, fand die Verweisung an den Ersten Ausschuß die erforderliche Unterstützung. In der Fassung "Examination of the Question of the Reservation Exclusively for Peaceful Purposes of the Sea-Bed and the Ocean Floor, and the Subsoil thereof, Underlying the High Seas Beyond the Limits of Present National Jurisdiction, and the Uses of their Resources in the Interests of Mankind" wurde der Punkt schließlich an diesen Ausschuß verwiesen ${ }^{95}$.

Es erscheint jedoch fraglich, ob man mit Recht davon sprechen kann, durch diese zugegebenermaßen mehr als nur redaktionelle Änderung sei der Vorschlag Maltas verwässert worden ${ }^{96}$. Die von Malta befürworteten Maßnahmen wären nämlich, sofern sie tatsächlich schon jetzt von der Vollversammlung beschlossen worden wären, eher als eine Art Kraftakt anzusprechen gewesen, mit dem letzten Endes niemand gedient wäre. Das gilt besonders, wenn es richtig wäre, daß - wie der Delegierte Maltas, Dr. Arvid Pardo, zur Begründung des Vorschlages ausführte $^{97}$ - in diesem Bereich ein rechtliches Vakuum auszufüllen ist. Man darf auch nicht übersehen, daß zwischen den objektiv notwendigen Maßnahmen und den im Rahmen der Vereinten Nationen möglichen Maßnahmen aus den wohl bekannten Gründen oft ein erheblicher Unterschied besteht. Die Beschränkung des Themas auf eine eingehende Prüfung der durch die Nutzung des Bodens und Untergrundes der Tiefsee aufgeworfenen Fragen ist daher in der Hinsicht sogar zu begrüßen, als sie genau dem entspricht, was die Vereinten Nationen im Augenblick leisten können, sie also nicht überfordert. Schließlich haben auch die nachfolgenden Beratungen im Ersten Ausschuß gezeigt, wie vordringlich eine solche Prüfung angesichts der vielen Unklarheiten ist, die auf diesem Gebiet noch bestehen.

Die Tatsache, daß der Punkt selbst doch noch an den Ersten Ausschuß verwiesen wurde, ist nicht nur als ein persönlicher Erfolg Dr. Pardos anzusehen, sondern auch als ein erfolgversprechender Ansatz für die zukünftige Aktivität der Vereinten Nationen. Sie läßt nämlich die richtige Einschätzung erkennen,

95 Nähere Einzelheiten über diese Beratungen finden sich außer in den offiziellen Dokumenten auch bei Weissberg, Guenter: International Law meets short-term national Interest: The Maltese Proposal on the Sea-Bed and Ocean Floor - Its Fate in two Cities, in: The International and Comparative Law Quarterly, Bd. 18 (1969), S. 41-102 (48 ff.)

96 So War/Peace Report, Bd. 7 (1967), Nr. 9, S. 10

97 Nach Weissberg, a. a. O., S. 48. 
daß es bei den angeschnittenen Problemen letztlich um ein Politikum geht, und zwar um die Entscheidung der Frage, wie die Nutzung des Bodens und Untergrundes der Tiefsee de lege ferenda geregelt werden soll. Das enthebt selbstverständlich nicht der Notwendigkeit, zuvor die gegenwärtige Rechtslage eingehend zu prüfen, zumal es sicher nicht zutrifft, daß hier ein totales rechtliches Vakuum besteht, wie oft behauptet wird ${ }^{98}$. Vielmehr ist mit Young ${ }^{99}$ darauf hinzuweisen, daß der ozeanische Raum im Gegensatz zum Weltraum, mit dem man ihn gern vergleicht, durch eine mehrhundertjährige Rechtsențicklung gekennzeichnet ist, über deren Ergebnisse man nicht einfach hinweggehen kann. Dennoch dürfte das Schwergewicht der Problematik auf lange Sicht schon deshalb im Politischen liegen, weil das bestehende Völkerrecht den mit der geschilderten Entwicklung sich abzeichnenden Formen der Nutzung des Bodens und Untergrundes der T'iefsee in Zukunft wohl kaum noch gerecht werden wird. Daher wird auch eine Kodifikation des bestehenden Rechts zur Beseitigung der bei den bisherigen Beratungen zutage getretenen Rechtsunsicherheit nicht ausreichen, sondern eine Anpassung an die veränderten Umstände erforderlich sein.

Das Gefühl der Unzulänglichkeit des gegenwärtigen Völkerrechts überwog auch in der Diskussion des Ersten Ausschusses. Hierbei war es wieder das Verdienst Dr. Pardos, in seiner Eröffnungsrede vielen Delegierten die Probleme überhaupt erst nahe gebracht zu haben ${ }^{100}$. Dr. Pardo setzte sich hierbei erneut dafür ein, den Boden und Untergrund der Tiefsee einer internationalen Kontrolle zu unterstellen. Aus rein praktischen Gründen würde es sich aber nicht empfehlen, die Vereinten Nationen selbst mit dieser Kontrollfunktion zu versehen. Das Vetorecht im Sicherheitsrat könne eine wirksame Ausübung der Kontrollrechte vereiteln, und die Gleichheit des Stimmrechts in der Vollversammlung werde dem besonderen Interesse der Großmächte an den Entscheidungen des Kontrollorgans, welches als Treuhänder für alle Staaten tätig werden solle, nicht gerecht ${ }^{101}$. An der Rede ist weiter bemerkenswert die Wiederholung des Vorschlages, die Vollversammlung solle in einer Resolution den Boden und Untergrund der Tiefsee zum gemeinsamen Erbe der Menschheit erklären, das nur für friedliche $Z_{\text {wecke }}$ und im Interesse der ganzen Menschheit unter besonderer Berücksichtigung der Bedürfnisse der Entwicklungsländer zu nutzen sei ${ }^{102}$. Besonders die Qualifikation des Tiefsee-Bodens als gemeinsames Erbe der Menschheit, welches im Interesse der ganzen Menschheit zu nutzen und daher der Unterwerfung unter die ausschließliche Hoheitsgewalt einzelner Staaten entzogen sei, könnte ein zukunftsweisender Ausgangspunkt für die weiteren Auseinandersetzungen sein. Zwar handelt es sich dabei im Kern nicht um ein neues Völkerrechtsprinzip ${ }^{103}$, sondern um die Einkleidung des altbewährten Grundsatzes der Freiheit der Meere in ein neues Gewand. Dessen innere Rechtfertigung liegt ja nicht in der mangelnden Beherrschbarkeit und Bestimmbarkeit des Hohen Meeres, sondern in der dem Hohen Meer durch die Rechtsüberzeugung der Völkerrechtsgemeinschaft verliehenen Bestimmung, „der Nutzung und dem Nutzen aller Völker zu dienen“104.

\footnotetext{
98 So zum Beispiel auch Levy, a. a. O., S. 135.

99 Vgl. Regime, S. 642.

$100 \mathrm{Vgl}$. War/Peace Report, Bd. 7 (1967), Nr. 9, S. 10.

101 Die Ubertragung der Kontrolle an die Vereinten Nationen war von vornherein nicht das Ziel des maltesischen Vorschlages; vgl. Pardo, Address, S. 225.

102 Eine Wiedergabe des wesentlichen Inhalts der Rede findet sich außer bei Weissberg, a. a. O., S. $49 \mathrm{ff}$. im UN Monthly Chronicle, Bd. 5 (1968), Nr. 1, S. 29 ff.

103 So Pardo, Address, S. 225. 1960, S. 791-795 (791 f.).
} 
Angesichts der verhängnisvollen, allein vom nationalstaatlichen Egoismus diktierten Rechtsentwicklung im Bereich des Festlandsockels scheint aber eine Rückbesinnung auf diesen auch für den Boden und Untergrund des Hohen Meeres geltenden Grundsat $\mathrm{z}^{105}$ dringend geboten, um eine Wiederholung dieser Entwicklung $\mathrm{zu}$ vermeiden. Schließlich verdient an der Eröffnungsrede außer dem Vorschlag zur Demilitarisierung des Bodens und Untergrundes der Tiefsee auch der Gedanke, seine Ausbeutung müsse im Interesse der ganzen Menschheit erfolgen und besonders die Bedürfnisse der Entwicklungsländer berücksichtigen, nicht nur wegen des Stimmengewichts dieser Länder in der Vollversammlung Beachtung. Enthält er doch einen Ansatz für die Einfügung sozialer Gesichtspunkte in das Recht, eine Tendenz, die im nationalen Bereich bereits in der Anerkennung des Prinzips der Sozialstaatlichkeit ihre Anerkennung gefunden hat ${ }^{\mathbf{1 0 6}}$, aber auch in den internationalen Beziehungen ständig an Bedeutung gewinnt ${ }^{107}$.

Die Reaktion der hiermit vor allem angesprochenen Industrienationen auf die Äußerungen Dr. Pardos läßt allerdings befürchten, daß sich seine „idealistischen“ Vorstellungen nur schwer durchsetzen werden. Zwar stellten die Delegierten vieler Entwicklungsländer diesen Gedanken in ihren Stellungnahmen besonders heraus $^{108}$ und die Delegierten Libyens und Somalias unterstützten die Vorschläge Maltas sogar vollen Umfangs ${ }^{\mathbf{1 0 9}}$. Aber zum Beispiel die Rede, die Arthur J. Goldberg als Repräsentant des reichsten Landes der Erde am 8. November 1967 im Ersten Ausschuß hielt, ging mit keinem Wort darauf ein ${ }^{110}$. Er betonte lediglich den Standpunkt seiner Regierung, der Boden der Tiefsee dürfe nicht zum Objekt einer neuen Form kolonialer Eroberung werden. Die angeschnittenen Fragen müßten aber zunächst einer sorgfältigen Prüfung unterzogen werden. Seine Regierung rege daher die Bildung eines ständigen "Committee on the Oceans" nach dem Vorbild des Weltraum-Ausschusses an ${ }^{111}$. Dieses solle alle Vorschläge, die an die Vollversammlung zu diesem Fragenkomplex herangetragen werden würden, prüfen und hierzu ihrerseits Empfehlungen für die Vollversammlung ausarbeiten. Es solle die Vollversammlung bei der Förderung langfristiger internationaler Zusammenarbeit auf dem Gebiet der Meeresforschung unterstützen und ihr bei der Erörterung rechtlicher Fragen, einschließlich solcher Punkte wie der Nutzungs- und Ausbeutungsrechte, der Rüstungskontrolle und der Meeresverschmutzung helfend zur Seite stehen. Wegen der besonderen Beachtung, die die Rüstungskontrolle verdiene, solle der vorgeschlagene Ausschuß eng mit dem Abrüstungs-Ausschuß zusammenarbeiten. $\mathrm{Da}$ der amerikanische Delegierte sich zunächst dem Vorschlag Maltas gegenüber so außerordentlich positiv geäußert hatte, läßt sich diese sehr allgemein gehaltene Stellungnahme nur als Reaktion auf die ungewöhnliche scharfe und zum Teil geradezu UNfeindliche Kritik erklären, die seine ursprüngliche Haltung im amerikanischen Kongreß erfahren hatte. Dort hatte sich zum Beispiel der Abgeordnete Paul A. Rogers aus Florida sogar zu der Äußerung verstiegen, wie bei der Eroberung

\footnotetext{
$105 \mathrm{Vgl}$. Böhmert, Viktor: Meeresfreiheit und Schelfproklamationen, in: Jahrbuch für Internationales Recht, Bd. 6 (1955), S. 7-99 (81 ff.). Im folgenden zitiert als Meeresfreiheit.

106 Vgl. zum Beispiel die Art. 20 und 28 des Grundgesetzes für die Bundesrepublik Deutschland vom 23. 5. 1949 (Amtlicher Text: Bundesgesetzblatt S. 1).

107 Vgl. Woods, George D.: The Development Decade in the Balance, in: Waters, Maurice: The United Nations, New York/London 1967, S. 450-456.

108 Vgl. UN Monthly Chronicle, Bd. 5 (1968), Nr. 1, S. 32.

109 Vgl. UN Monthly Chronicle, Bd. 5 (1968), Nr. 1, S. 30.

110 Englischer Text: The Department of State Bulletin vom 27.11. 1967, S. 723.

111 Dieser Vorschlag hatte nach der Außerung eines hohen Beamten des amerikanischen Innenministeriums aber vor allem den Sinn, die Vereinigten Staaten in den Vereinten Nationen nicht dem Vorwurf auszusetzen, sie nehme bei der Beantwortung der aufgeworfenen Fragen eine rein negative Haltung ein; vgl. Weissberg, a. a. O., S. 53.
} 
des amerikanischen Westens gehe es hier lediglich um die Ausdehnung der nationalen Hoheitsgrenzen und das Ziel sei die Okkupation des bis zum MittelAtlantik reichenden Gebietes bis zum Jahre 1980112. Unter diesen Umständen muß die Bemerkung des Delegierten Goldberg, alles Wissen über den Boden der Tiefsee und alle technologischen Fertigkeiten zur Ausbeutung seiner Naturschätze könnten sich als von geringem Wert erweisen, wenn die Fähigkeit zu ihrer rechtlichen Bewältigung nicht Schritt halte, leider als eine mehr persönliche Äußerung gewertet werden ${ }^{113}$.

Der amerikanische Vorschlag zur Einsetzung eines ständigen Ausschusses wurde zwar von den Delegierten Australiens, Brasiliens, Ghanas, Griechenlands, Jamaicas, der Niederlande, Norwegens, Schwedens und Venezuelas unterstützt. Er hatte aber von vornherein keine Aussicht auf Verwirklichung, da sich die Delegierten Boliviens, Bulgariens, Indiens, Irans, Islands, Polens, Jugoslawiens und vor allem der Sowjetunion dagegen aussprachen ${ }^{114}$. Aus den Außerungen des sowjetischen Delegierten war darüber hinaus zu entnehmen, daß die ablehnende Haltung seines Landes sich nicht nur auf die Einsetzung des vorgeschlagenen Ausschusses bezog, sondern auch auf die Einschaltung der Vereinten Nationen in diesen Fragenkomplex überhaupt. Selbst die vorbereitenden Arbeiten für eine Erörterung der mit dem Vorschlag Maltas angesprochenen Probleme sollten seiner Auffassung nach am besten die Mitgliedstaaten selbst durchführen. Nach Abschluß dieser Vorarbeiten sollte dann der UN-Generalsekretär den Auftrag erhalten, in Zusammenarbeit mit der Zwischenstaatlichen Ozeanographischen Kommission der UNESCO und anderer betroffener internationaler Organisationen einen ausführlichen Bericht über die bisher geleistete Arbeit, über deren Koordinierung und über die Organisation einer internationalen Zusammenarbeit auf diesem Gebiet zu erstellen. Sein Bericht würde den Mitgliedstaaten als nützliche Entscheidungshilfe hinsichtlich der Frage dienen können, welche Maßnahmen die Vereinten Nationen ergreifen könnten und sollten ${ }^{114}$.

An der somit ausgesprochen negativen Stellungnahme des sowjetischen Delegierten ist jedoch hervorzuheben, daß er ebenso wie der amerikanische Delegierte der Frage der militärischen Nutzung des Tiefsee-Bodens besondere Aufmerksamkeit schenkte. Beides deutet darauf hin, daß die Großmächte in diesem Aspekt, und zwar vor allem im Zusammenhang mit dem Problem der atomaren Abrüstung das eigentliche Problem erblicken. Dabei lassen einige Vorstöße der Sowjetunion in der jüngsten Zeit ${ }^{115}$, insbesondere Art. 3 der Gemeinsamen Deklaration der Regierungen der Deutschen Demokratischen Republik, Polens und der Sowjetunion über die Abgrenzung und Nutzung des Festlandsockels in der Ostsee vom 23. Oktober $1968^{116}$ vermuten, daß die Sowjetunion eine Entmilitarisierung des gesamten Meeresbodens außerhalb der Küstenmeere anstrebt. Das Hauptaugenmerk der Vereinigten Staaten scheint dagegen darauf gerichtet zu sein, die Nutzung des Tiefsee-Bodens als Abschußbasis für atomare Massenvernichtungsmittel zu verhindern ${ }^{117}$. Die Frage der militärischen Nutzung wurde auch von den Delegierten einer Reihe anderer Staaten angesprochen. Wohl in der Befürchtung, die Diskussionen seien von vornherein zum Scheitern verurteilt, wenn dieses Problem nicht abgetrennt werden würde, sprachen sich jedoch unter

112 Nach Weissberg, a. a. O., S. 45.

$113 \mathrm{Vgl}$. The Department of State Bulletin vom 27.11. 1967, S. 724

114 Vgl. UN Monthly Chronicle, Bd. 5 (1968), Nr. 1, S. 30 f.

115 Vgl. hierzu Swirin, a. a. O., S. 6.

116 Deutscher Text: Neues Deutschland vom 24. 10. 1968.

$117 \mathrm{Vgl}$. Department of State Bulletin vom 5. 8. 1968, S. 152. 
anderem die Delegierten von Belgien, Canada, Großbritannien, Irland, Italien, den Niederlanden und der Sowjetunion dafür aus, es im Rahmen des AbrüstungsAusschusses zu behandeln ${ }^{118}$.

Angesichts der geschilderten kontroversen Auffassungen gewann bald eine vermittelnde Meinung an Bedeutung, die der Einsetzung eines ad-hoc-Ausschusses das Wort redete. Dieser solle unter anderem die rechtliche, wirtschaftliche und politische Seite des Fragenkomplexes prüfen ${ }^{119}$. Über die präzise Aufgabenstellung eines solchen vorbereitenden Ausschusses kam es zwar noch zu längeren Auseinandersetzungen und hierbei trat auch die Unvereinbarkeit der Standpunkte $\mathrm{zu}$ den entscheidenden rechtlichen Fragen wieder deutlich in Erscheinung. Es gelang dann aber dem belgischen Delegierten Roger Denorme, einen Resolutionsentwurf zu formulieren, der im Gegensatz zum Vorschlag Maltas jedes Präjudiz für die künftigen Diskussionen ängstlich vermied ${ }^{120}$. Úber die Zahl der Ausschußmitglieder konnte man sich zunächst ebenfalls nicht einigen, und ein erster Resolutionsentwurf, der die Mitgliederzahl auf 30 beschränkte, kam über das Beratungsstadium nicht hinaus. Während der folgenden Erörterungen einigte man sich jedoch dahingehend, daß der Ausschuß aus 35 Mitgliedern bestehen solle. In dieser abgeänderten Form fand der belgische Resolutionsentwurf schließlich die Unterstützung von 43 Delegationen und am 8. Dezember 1967 mit 93 Ja-Stimmen, keiner Gegenstimme und einer Enthaltung (Gabun) auch die Zustimmung des Ersten Ausschusses ${ }^{121}$. Hiermit wurde einer Forderung entsprochen, die während der vorangegangenen Ausschußberatungen schon der Delegierte Mexikos erhoben hatte, daß nämlich der Erste Ausschuß möglichst einstimmig entscheiden solle ${ }^{122}$. Diese Forderung mag auf den ersten Blick etwas formal erscheinen. Doch der darin enthaltene Gedanke, daß alle Maßnahmen der Vereinten Nationen auf dem Gebiet der Nutzung des Bodens und Untergrundes der Tiefsee von der Zustimmung einer möglichst großen Zahl von Mitgliedstaaten getragen sein sollten, ist schon deswegen von großer Bedeutung, weil nicht alle Staaten mit maritimen Interessen Mitglied der Vereinten Nationen sind. Wenn nämlich nicht einmal die ganz überwiegende Mehrheit der Mitgliedstaaten hinter den Maßnahmen der Vereinten Nationen steht, werden sie die NichtMitglieder kaum als für sich richtungsweisend anerkennen und durch ein entsprechendes Verhalten zur Herausbildung einer einheitlichen allgemeinen Praxis beitragen. Ebensowenig besteht für völkerrechtliche Verträge, die möglicherweise das Ergebnis der Erörterungen in den Vereinten Nationen sein werden, die Aussicht, daß Nicht-Mitglieder sie unterzeichnen und ratifizieren oder ihnen beitreten werden, wenn sie nicht von der Mehrheit der Mitgliedstaaten unterzeichnet und ratifiziert worden sind. Sofern sie nicht wenigstens von einer solchen Mehrheit praktiziert werden, werden sie auch keine Anerkennung als allgemein verbindliches Völkergewohnheitsrecht erlangen können.

Die einmütige Haltung des Ersten Ausschusses wirkte sich schon während der weiteren Beratungen in den Vereinten Nationen aus. Am 18. Dezember 1967 nahm die Vollversammlung auf ihrer 1639. Plenarsitzung mit 99 Ja-Stimmen ohne Gegenstimmen und Enthaltungen entsprechend dem Bericht des Ersten Ausschusses eine Resolution an, in der die Einsetzung eines „Ad Hoc Committee

118 Vgl. UN Monthly Chronicle, Bd. 5 (1968), Nr. 1, S. 33.

$119 \mathrm{Vgl}$. zum Beispiel die Stellungnahme des belgischen Delegierten; UN Monthly Chronicle, Bd. 5 (1968), Nr. 1, S. 33 .

$120 \mathrm{Vgl}$. hierzu ausführlich Weissberg, a. a. O., S. $57 \mathrm{ff}$.

121 Vgl. UN Monthly Chronicle, Bd. 5 (1968), Nr. 1, S. 34

122 Vgl. UN Monthly Chronicle, Bd. 5 (1968), Nr. 1, S. 32. 
to Study the Peaceful Uses of the Sea-Bed and the Ocean Floor Beyond the Limits of National Jurisdiction", dem 35 Staaten angehören, beschlossen wurde ${ }^{123}$. Dem ad-hoc-Ausschuß wurde die Aufgabe gestellt, in Zusammenarbeit mit dem Generalsekretär eine Studie für die Beratungen der Vollversammlung in der 23. Sitzungsperiode vorzubereiten. Die Studie sollte enthalten:

1. einen Überblick über die bisherige und gegenwärtige Tätigkeit der Vereinten Nationen, ihrer Unterorganisationen, der Internationalen Atomenergie-Behörde und anderer zwischenstaatlicher Organisationen in diesem Bereich,

2. eine Aufstellung der wissenschaftlichen, technischen, wirtschaftlichen, rechtlichen und sonstigen Aspekte dieses Fragenkomplexes und

3. Hinweise auf praktische Wege zur Förderung der internationalen Zusammenarbeit bei der Erforschung, Erhaltung und Nutzung der in Frage stehenden Gebiete.

Außerdem ersuchte die Vollversammlung in der Resolution den Generalsekretär unter anderem, ihren Wortlaut den Regierungen aller Mitgliedstaaten zuzuleiten, um deren Haltung zu den aufgeworfenen Fragen zu eruieren. Schließlich wurden die Unterorganisationen, die Internationale Atomenergie-Behörde und sonstige zwischenstaatliche Organisation aufgefordert, zur Verwirklichung der Resolution mit dem ad-hoc-Ausschuß voll zusammenzuarbeiten.

Der ad-hoc-Ausschuß nahm im Frühjahr 1968 seine Arbeit auf und wählte auf seiner ersten, in der Zeit vom 18. bis 27. März 1968 in New York abgehaltenen Sitzung den Ceylonesen H. S. Amerasinghe zu seinem Vorsitzenden. Die Arbeit selbst wurde in der Weise organisiert, daß eine Arbeitsgruppe für die rechtlichen Fragen und eine zweite für die technischen und wirtschaftlichen Fragen eingerichtet wurde. Der Ausschuß als Ganzes sollte sich den politischen Aspekten und den Möglichkeiten internationaler Zusammenarbeit auf diesem Gebiet widmen sowie die Aktivität der beiden Arbeitsgruppen koordinieren ${ }^{124}$.

Die eigentliche sachliche Arbeit wurde jedoch hauptsächlich erst während der zweiten Sitzung geleistet, die am 17. Juni 1968 in New York begann. Wie schon in den vorangegangenen Beratungen im Ersten Ausschuß zeigten sich einerseits vor allem die Sowjetunion und die Vereinigten Staaten im Hinblick auf den Inhalt einer zukünftigen Regelung der friedlichen Nutzung sehr zurückhaltend. Andererseits wurde auch hier wieder sichtbar, welche Bedeutung die beiden Staaten und andere Mächte den Fragen der militärischen Nutzung zumessen. Zum Beispiel legte die Sowjetunion einen Resolutionsentwurf vor, der die Regierungen aufforderte, die in Frage stehenden Gebiete ausschließlich für friedliche Zwecke zu nutzen, und den Abrüstungs-Ausschuß ersuchte, die Frage eines Verbotes der Nutzung für militärische Zwecke zu erwägen ${ }^{125}$. Nach einem von den Vereinigten Staaten vorgelegten Resolutionsentwurf sollte der Abrüstungs-Ausschuß von der Vollversammlung ersucht werden, die Frage der Rüstungsbegrenzung auf dem Boden der Tiefsee aufzugreifen mit dem Ziel, die Bedingungen für eine Vereinbarung zu bestimmen, welche wirksam die Deponierung von Massenvernichtungswaffen verhindern könnte126. Der Delegierte Indiens legte sogar - allerdings wohl reichlich verfrüht - einen Resolutionsentwurf vor, der nach dem Vorbild des Verfahrens beim Weltraum-Vertrag bereits als Grundlage für einen entsprechenden Vertrag

123 Amtlicher Text: U.N. Doc. A/Res/2340 (XXII) vom 28. 12. 1967; Englischer Text: International Legal Materials 1968, S. 174.

124 Vgl. UN Monthly Chronicle, Bd. 5 (1968), Nr. 4, S. 50 f.

125 Vgl. UN Monthly Chronicle, Bd. 5 (1968), Nr. 7, S. 47.

126 Amtlicher Text: The Department of State Bulletin vom 5. 8. 1968, S. 152. 
über den Boden der Tiefsee gedacht war und die Nutzung des Tiefsee-Bodens ausschließlich auf friedliche Zwecke beschränkte ${ }^{127}$. Dieses äußerliche Bild einer Übereinstimmung der Standpunkte darf jedoch nicht darüber hinwegtäuschen, wie weit die Auffassungen in Wirklichkeit noch voneinander entfernt waren und wohl auch heute noch sind. Man kann nämlich zwar den Begriff der Deponierung von Massenvernichtungswaffen auf dem Boden der Tiefsee - was besonders im Hinblick auf die Kontrolle der Einhaltung eines Vertrages wichtig wäre - objektiv bestimmen. Der Begriff der Nutzung für friedliche Zwecke ist aber nicht nur im Hinblick auf die Besonderheiten der sowjetischen Völkerrechtsdoktrin $^{128}$, sondern auch wegen seines subjektiven Gehalts sehr vage, vergleichbar mit dem der Verteidigungswaffe. Zum Beispiel wird in den Augen der Sowjetunion die Installation amerikanischer U-Boot-Warn- und -Verfolgungssysteme auf dem Boden der Tiefsee kaum als friedliche Nutzung angesehen werden. Umgekehrt werden aber die Vereinigten Staaten langfristig kaum auf solche zum Schutze ihrer Küsten notwendigen Installationen verzichten können ${ }^{129}$. Dementsprechend verwundert es nicht, wenn ein amerikanisches Mitglied des ad-hoc-Ausschusses noch am 10. Juli 1968 die Auffassung vertrat, es gäbe keine Anzeichen für eine Bereitschaft der Sowjetunion, in ernsthafte Diskussionen über dieses Thema einzutreten ${ }^{\mathbf{1 3 0}}$.

In bezug auf die friedliche Nutzung ergibt sich ein ähnliches Bild bei einem Vergleich des genannten indischen Resolutionsentwurfes mit einem von den Vereinigten Staaten eingebrachten Entwurf über die Feststellung von Prinzipien betreffend den Boden der Tiefsee. Zwar enthielten beide Entwürfe die Feststellung, der Boden der Tiefsee könne nicht Gegenstand nationaler Hoheitsrechte sein. Aber auch hier steckte der Teufel wieder im Detail. So bestimmte der Resolutionsentwurf Indiens, daß der Boden der Tiefsee im Interesse aller Staaten, besonders aber der Entwicklungsländer, genutzt werden solle ${ }^{131}$. Dagegen sollten nach dem amerikanischen Entwurf lediglich, sobald das tunlich sei, völkerrechtliche Vereinbarungen über die Ausbeutung seiner Naturschätze geschlossen werden. Erst in diese Verträge sollte dann unter anderem das Prinzip aufgenommen werden, daß ein „as feasable and practicable“ Teil des Wertes der aus dem Tiefsee-Boden gewonnenen Rohstoffe für Zwecke der Völkergemeinschaft bestimmt werden solle ${ }^{132}$. Daß es den Vereinigten Staaten mit solchen Vereinbarungen allerdings nicht besonders eilig ist, muß zumindest den Außerungen ihres Delegierten David H. Popper entnommen werden. Dieser wies nämlich kurze Zeit nach der zweiten Sitzung des ad-hoc-Ausschusses bei anderer Gelegenheit darauf hin, daß besagter Resolutionsentwurf von vornherein eher als Anregung für die Diskussion denn als abschließende Stellungnahme gedacht sei133. Andererseits dürften die Vereinigten Staaten als eines der Länder, deren Wirtschaft wahrscheinlich zuerst und am intensivsten die Naturschätze des Bodens und

127 Vgl. UN Monthly Chronicle, Bd. 5 (1968), Nr. 7, S. 48 f.

128 Vgl. zum Beispiel die Ausführungen über die Aggression bei Levin-Kaljusnaja: Völkerrecht, deutsche Ubersetzung Berlin 1967, S. 397.

129 In diesem Zusammenhang ist der von Senator Clairborne Pell am 5. 3. 1968 im amerikanischen Senat eingebrachte Entwurf eines Vertrages über die Prinzipien der Erforschung des ozeanischen Raumes bemerkenswert, der solche Installationen erlaubt; vgl. Weissberg, a. a. O., S. $91 \mathrm{f}$.

130 Nach Weissberg, a. a. O., S. 97; vgl. auch Popper, David H.: The Deep Ocean Environment: U.S. and International Policy, in: The Department of State Bulletin vom 12. 8. 1968, S. 171-177 (176). Umgekehrt werden von sowjetischer Seite die gleichen Vorwürfe erhoben; vgl. Kalinkin, G.: Military Use of the Sea-Bed should be banned, in: International Affairs (Moskau) 1969, Nr. 2, S. 45-48.

131 Vgl. UN Monthly Chronicle, Bd. 5 (1968), Nr. 7, S. 48 f.

132 Amtlicher Text: The Department of State Bulletin vom 5. 8. 1968, S. 152; vgl. dazu auch die Ausführungen von Peter S. Thacher im Ad-Hoc-Ausschuß vom 9.7. 1968, deren Wortlaut in derselben Ausgabe des Bulletin (S. 150-152) abgedruckt ist.

133 Vgl. Popper, a. a. O., S. 174. 
Untergrundes der Tiefsee ausbeuten wird, doch ein reales Interesse an dem Zustandekommen vertraglicher Abmachungen haben. Augenscheinlich hat man dort nämlich erkannt, daß sie ein Mittel zum Schutze amerikanischer Investitionen auf diesem Sektor sein könnten ${ }^{134}$.

Die Vereinigten Staaten standen und stehen aber mit ihrer abwartenden Haltung hinsichtlich einer zukünftigen Regelung der friedlichen Nutzung nicht allein. Ihre in mancher Beziehung sogar hinhaltende Verhandlungstaktik ${ }^{\mathbf{1 3 5}}$ repräsentiert vielmehr im großen und ganzen die Auffassung und das Verhalten der meisten großen Industrienationen einschließlich der Sowjetunion gegenüber den Forderungen der Entwicklungsländer ${ }^{136}$. Die insoweit zu beobachtende eigenartige Spaltung der Interessenlage der Industrienationen, nämlich die Übereinstimmung der Interessen in bezug auf die friedliche Nutzung auf der einen und die Interessengegensätze hinsichtlich der militärischen Nutzung auf der anderen Seite, könnte sich in Zukunft vielleicht sogar als das Haupthindernis für das Zustandekommen einer vertraglichen Regelung erweisen ${ }^{137}$. Hinzu kommt, daß die Interessenlage der Entwicklungsländer ebenfalls nicht einheitlich ist. Während nämlich einigen dieser Staaten lediglich an einer Art "Gewinnbeteiligung" gelegen sein dürfte, kommt es für andere vor allem darauf an, Vorkehrungen gegen einen Preisverfall bestimmter, von ihnen exportierter Rohstoffe zu treffen.

Die geschilderten Interessengegensätze konnten auch auf der dritten und letzten Sitzung des ad-hoc-Ausschusses, die vom 19. bis 30. August 1968 in Rio de Janeiro abgehalten wurde, nicht überbrückt werden. Dementsprechend wird in dem dort erarbeiteten Abschlußbericht ${ }^{138}$ festgestellt, daß der Ausschuß die verschiedenen Aspekte des Fragenkomplexes untersucht und die wichtigsten Probleme ermittelt habe, aber eine weitere Prüfung erforderlich sei. Obwohl man sich bis zum Ende der Sitzung darum bemüht und beträchtliche Fortschritte erzielt habe, sei es nicht mehr gelungen, ein abschließendes Übereinkommen zu erzielen, dem einmütige Unterstützung zuteil geworden wäre. Hierzu ist anzumerken, daß während der Beratungen des ad-hoc-Ausschusses wiederholt die Auffassung vertreten worden war, es sei zunächst erforderlich, einen Katalog von Grundsätzen auszuarbeiten, die für die Nutzung des Bodens und Untergrundes der Tiefsee maßgeblich sein sollten ${ }^{139}$. Zwei solcher Kataloge standen außer den bereits genannten Resolutionsentwürfen auf der letzten Sitzung zur Diskussion. Der erste war von 15 Entwicklungsländern vorgeschlagen worden, erfreute sich also der Unterstützung fast der Hälfte der Ausschußmitglieder. Leider muß man bezüglich dieses Kataloges - besonders im Hinblick auf die Tatsache, daß die Delegierten einiger Entwicklungsländer während der vorangegangenen Diskussion im Ersten und im ad-hoc-Ausschuß mit einem gewissen Recht den Industrienationen eine negative Haltung vorgeworfen hatten ${ }^{140}$ - feststellen, daß er wegen seiner einseitigen Betonung der Interessen der Entwicklungsländer kaum als konstruktiv $\mathrm{zu}$ bezeichnen ist ${ }^{141}$. Abgesehen von den sowieso durch die meisten Delegierten unterstützten Grundsätzen, daß kein Staat auf dem Boden der Tiefsee Hoheits-

134 Vgl. dazu besonders Ziff. 2 (b) des amerikanischen Resolutionsentwurfes, a. a. O., S. 153.

135 Hierher dürfte zum Beispiel der Vorschlag gehören, bestimmte Gebiete für wissenschaftliche Zwecke und unter dem Gesichtspunkt des Naturschutzes von einer Nutzung auszuschließen; vgl. The Department of State Bulletin vom 22. 7. 1968, S. 104-107 (106 f.).

$136 \mathrm{Vgl}$. hierzu ausführlicher Weissberg, a. a. O., S. $97 \mathrm{ff}$. Zur Haltung speziell der Sowjetunion vgl. auch Kalinkin, a. a. O., S. 48.

137 In Wirklichkeit ist die Interessenlage leider noch viel komplizierter; vgl. dazu u. a. Popper, a. a. O., S. 173.

138 Offizieller Text: U.N. Doc. A 7230. Vgl. auch UN Monthly Chronicle, Bd. 5 (1968), Nr. 8, S. 98.

139 Vgl. zum Beispiel UN Monthly Chronicle, Bd. 5 (1968), Nr. 7, S. 48.

140 Vgl. Weissberg, a. a. O., S. 56 f., 101.

141 Zum Inhalt dieses Vorschlages vgl. UN Monthly Chronicle, Bd. 5 (1968), Nr. 8, S. 98. 
rechte ausüben dürfe und seine Erforschung, Nutzung und Ausbeutung nur zu friedlichen Zwecken erfolgen dürfe, ging dieser Katalog auf grundlegende Fragen entweder überhaupt nicht oder nur sehr allgemein ein. Man vermißt selbst konkrete Vorschläge darüber, in welcher Art und Weise denn den besonderen Bedürfnissen der Entwicklungsländer Rechnung getragen werden solle.

Demgegenüber enthielt der zweite von Großbritannien vorgeschlagene Katalog zunächst die wichtige, weil unter Berufung auf Art. 1 der Festlandsockel-Konvention von namhaften Autoren ${ }^{142}$ bestrittene Feststellung, daß es Teile des Meeresbodens gibt, die außerhalb der Grenzen nationaler Jurisdiktion liegen. Weiter betonte er die Notwendigkeit einer genauen Abgrenzung dieser Gebiete sowie einer Vereinbarung von Regeln über die Ausbeutung ihrer Naturschätze. Wie in dem erstgenannten Katalog, so findet sich auch in diesem die Feststellung, daß der Boden der Tiefsee nicht Gegenstand nationaler Hoheitsrechte sein könne, ausschließlich für friedliche Zwecke genutzt werden solle und seine Ausbeutung zum Wohle und im Interesse der ganzen Menschheit unter Berücksichtigung der besonderen Bedürfnisse der Entwicklungsländer erfolgen solle ${ }^{143}$.

$\mathrm{Da}$ man sich jedoch auf keinen der Entwürfe einigen konnte, fand ein Vorschlag Belgiens, einen ständigen Ausschuß für die friedliche Nutzung des Meeresbodens einzurichten, weitgehende Zustimmung. Die endgültige Entscheidung über seine Zusammensetzung und Aufgabenstellung wurde allerdings der 23. Sitzungsperiode der Vollversammlung vorbehalten ${ }^{144}$. Auch hinsichtlich der weiteren Behandlung der militärischen Probleme kam es zu keiner Einigung. Während vor allem die Großmächte Großbritannien, Sowjetunion und die Vereinigten Staaten diese Fragen im Abrüstungs-Ausschuß weiter erörtern wollten, sprachen sich die Delegierten anderer Staaten dafür aus, die Diskussion aller mit dem Boden der Tiefsee zusammenhängenden Fragen in einem einzigen Gremium zu konzentrieren ${ }^{145}$.

In den Beratungen über den Bericht des ad-hoc-Ausschusses im Ersten Ausschuß der Vollversammlung während ihrer 23. Sitzungsperiode zeigte sich keine Veränderung, sondern eher eine Erstarrung der Fronten. Die Diskussionen boten ein ähnliches Bild wie die Beratungen dieses Ausschusses in der vorangegangenen Sitzungsperiode, nur daß jetzt Aufgabenstellung und Zusammensetzung des vom ad-hoc-Ausschuß vorgeschlagenen ständigen Ausschusses Gegenstand der Auseinandersetzungen waren $^{146}$. Hierbei zeigten besonders die Ostblockstaaten eine unverhohlene Abneigung gegen jede Art von internationaler Verwaltung. Das Interesse der Sowjetunion an diesem Thema scheint sich auch - abgesehen von den militärischen Fragen - vor allem auf die Erhaltung des Fischreichtums der Ozeane zu konzentrieren ${ }^{147}$. Schließlich wurden vier Resolutionsentwürfe angenommen, die auch die Vollversammlung am 21. Dezember 1968 ohne Anderung passierten ${ }^{148}$.

Die erste Resolution (2467 A) hat die Einsetzung eines ständigen Ausschusses für die friedliche Nutzung des Meeresbodens und -untergrundes außerhalb der

$142 \mathrm{Vgl}$. zuletzt Oda, Shigeru: Some Observations on the International Law of the Sea, in: The Japanese Annual of International Law, Bd. 11 (1967), S. 37-50 (39 f.).

143 Vgl. UN Monthly Chronicle, Bd. 5 (1968), Nr. 8, S. 98 f.

144 Vgl. UN Monthly Chronicle, Bd. 5 (1968), Nr. 8, S. 99.

145 Vgl. UN Monthly Chronicle, Bd 5 (1968), Nr. 8, S 100.

146 Zum Verlauf der Beratungen vgl. UN Monthly Chronicle, Bd. 5 (1968), Nr. 11, S. 53 ff.; Bd. 6 (1969) Nr. 1, S. 56 ff.; Vereinte Nationen, Bd. 17 (1969), S. 23 ff.; Neue Zürcher Zeitung vom 23. 12.1968.

147 Bemerkenswerterweise unterstützte die Sowjetunion einen Resolutionsentwurf über Vorkehrungen zur Verhinderung von Meeresverschmutzungen; vgl. UN Monthly Chronicle, Bd. 5 (1968), Nr. 11, S. 54. Zur Haltung der Sowjetunion vgl. auch Kalinkin, a. a. O., S. 48.

148 Es handelt sich um die Resolutionen 2467 A-D (XXIII). Englischer Text: UN Monthly Chronicle, Bd. 6 (1969), Nr. 1, S. $58 \mathrm{ff}$. 
Grenzen nationaler Jurisdiktion zum Gegenstand. Er besteht aus 42 Staaten, also einem Drittel der UN-Mitglieder. Seine Aufgaben sind zum einen die Prüfung und Ausarbeitung von Prinzipien und Normen zur Förderung internationaler Zusammenarbeit bei der Ausbeutung und Nutzung des Tiefsee-Bodens und -Untergrundes und zum anderen die Sicherung der Ausbeutung ihrer Naturschätze zum Wohle der ganzen Menschheit. Er soll Mittel und Wege zur Förderung der Ausbeutung und Nutzung und der internationalen Zusammenarbeit auf diesem Sektor unter besonderer Berücksichtigung etwaiger wirtschaftlicher Auswirkungen sowie die Vorschläge zur Verhinderung der Meeresverschmutzung prüfen. Obwohl die Frage der militärischen Nutzung an den Abrüstungsausschuß verwiesen wurde ${ }^{149}$, soll sich der Ausschuß auch mit der Frage der Entmilitarisierung des Meeresbodens beschäftigen. Die zweite Resolution (2467 B) betrifft die Verhinderung der Meeresverschmutzung im Zusammenhang mit der Erforschung und Ausbeutung des Tiefsee-Bodens. In der Resolution 2467 C wird der Generalsekretär aufgefordert, die Frage der Errichtung einer geeigneten „international machinery“ zur Förderung der Erforschung und Ausbeutung der Naturschätze der fraglichen Gebiete, ihrer Nutzung im Interesse der Menschheit unabhängig von der geographischen Lage der Staaten und mit besonderer Berücksichtigung der Interessen und Bedürfnisse der Entwicklungsländer zu untersuchen ${ }^{150}$. Die vierte Resolution (2467 D) schließlich entspricht einer Anregung der Vereinigten Staaten, das Wissen über den Boden und Untergrund der Tiefsee in einer internationalen Dekade ozeanischer Forschung zu vergrößern.

Die genannten Resolutionen stellen einerseits einen vorläufigen Abschluß der Entwicklung dar; denn sie eröffnen den Vereinten Nationen ein so weites Betätigungsfeld, daß schon wegen des Umfangs der erforderlichen Studien wohl nicht so bald mit einem greifbaren Ergebnis zu rechnen ist. Der darin liegende Verzögerungseffekt hat auch bereits Anlaß zu Mißfallensäußerungen gegeben. Man muß aber gerechterweise anerkennen, daß die Resolutionen andererseits die Grundlage für langfristige Aktivitäten bilden, von denen noch einiges zu erwarten ist. Außerdem müssen selbst die schärfsten Kritiker zugeben, daß in der Schaffung des ständigen Ausschusses eine Entwicklung ihren institutionellen Niederschlag gefunden hat, die vor nicht ganz zwei Jahren, als Malta den Vorschlag machte, das Thema der Nutzung des Tiefsee-Bodens in den Vereinten Nationen zu beraten, nur wenige für möglich gehalten haben werden ${ }^{151}$. Es ist daher wohl auch zumindest verfrüht, die Tatsache, daß die bisherigen Beratungen noch zu keinem konkreten Ergebnis in der Sache selbst geführt haben, als einen weiteren Fall zu beklagen, in dem das kurzfristige nationale Interesse über zukunftsweisende Gedanken, deren Verwirklichung auf lange Sicht auch dem nationalen

149 Der Abrüstungsausschuß nahm am 18. März 1969 nach längerer Pause seine Beratungen in Genf wieder auf und machte die Frage der Entmilitarisierung des Meeresbodens zu seinem Hauptthema. Hierbei trat die zur Zeit noch bestehende Unvereinbarkeit des amerikanischen und des sowjetischen Standpunktes wie bei den vorangegangenen Erörterungen im ad-hoc-Ausschuß voll zu Tage; vgl. Die Welt vom 19.3 .1969$.

150 Für diese Resolution stimmten nur 85 Staaten. Neun Staaten des Ostblocks einschließlich der Sowjetunion stimmten dagegen. 25 Staaten - darunter Australien, Belgien, Canada, Frankreich, Großbritannien, Italien, Neuseeland, Südafrika und die Vereinigten Staaten - enthielten sich der Stimme; vgl. UN Monthly Chronicle, Bd. 6 (1969), Nr. 1, S. 58. Der Unterschied zu dem Abstimmungsergebnis bei den anderen Resolutionen, von denen die zweite und vierte einstimmig und die erste ohne Gegenstimme bei sieben Enthaltungen angenommen wurden, läßt vermuten, daß auf diesem Sektor nicht so schnell nennenswerte Fortschritte erzielt werden.

151 Damit drängt sich dann wieder die Frage auf, ob das Commonwealth-Mitglied Malta, dessen Delegierter bei den Vereinten Nationen, Dr. Pardo, als Botschafter seines Landes in den Vereinigten Staaten und der Sowjetunion eine außergewöhnliche Stellung einnimmt, nicht doch als Sprachrohr einer Großmacht oder gar der Vereinten Nationen? - die Behandlung des Themas in den Vereinten Nationen vorgeschlagen hat, wie das verschiedentlich behauptet wurde; vgl. War/Peace Report, Bd. 7 (1967), Nr. 9, S. 10; Weissberg, a. a. O., S. 44. 
Interesse am besten dienen würde, gesiegt hat ${ }^{152}$. Denn obwohl sich - wie ausgeführt wurde - auf dem Gebiet der Meeresforschung und -technik in den letzten Jahren eine wahrhaft atemberaubende Entwicklung vollzogen hat, ist das Wissen über die riesigen Gebiete des Tiefsee-Bodens und -untergrundes noch viel zu gering, um alle Nutzungsmöglichkeiten und ihre wirtschaftliche, militärische und sonstige Bedeutung auch nur annähernd abschätzen zu können. Man kann es daher den Staaten nicht verübeln, wenn sie vor Eingehung rechtlicher Verpflichtungen den Sachverhalt erst genauer klären wollen und bis dahin gegenüber allen Vorschlägen hinsichtlich der Ausgestaltung einer zukünftigen Regelung eine abwartende Haltung einnehmen. Auch ist dem Interesse aller Nationen auf lange Sicht nur dann gedient, wenn die schließlich erarbeitete Lösung von der Rechtsüberzeugung einer größtmöglichen Zahl von Staaten getragen wird. Eine solche Rechtsüberzeugung kann jedoch nur das Ergebnis einer fundierten Meinungsbildung sein, die ihrerseits einen genauen Einblick in die tatsächlichen Gegebenheiten und Sachzusammenhänge voraussetzt.

\section{III.}

Fragt man sich nun, was von der Einschaltung der Vereinten Nationen in das Problem der Nutzung des Bodens und Untergrundes der Tiefsee zu halten ist, so sind damit in Wirklichkeit zwei Fragen aufgeworfen. Die erste betrifft die Rolle der Vereinten Nationen in dem Prozeß der Erarbeitung einer befriedigenden Lösung. Davon zu unterscheiden ist die Frage, ob und gegebenenfalls welche Rolle die Vereinten Nationen im Rahmen einer zukünftigen Regelung spielen sollten. Um diese Fragen beantworten zu können, muß jedoch zuvor eine Antwort auf die Frage gefunden werden, ob denn überhaupt das Völkerrecht in seiner gegenwärtigen Ausgestaltung die Nutzung des Bodens und Untergrundes der Tiefsee unbefriedigend regelt und daher eine Neuregelung wünschenswert ist. Dazu ist unter anderem eine Klärung der gegenwärtigen Rechtslage erforderlich. Eingehende Erörterungen zu diesem Punkt würden allerdings den Rahmen dieser Ausführungen, die in erster Linie der Information und der Veranschaulichung der Probleme dienen sollen, sprengen. Es sollen deshalb lediglich einige grundlegende Fragen kurz angeschnitten werden.

Dabei ist zunächst auf die wiederholten Klagen einzugehen, daß es im Bereich der Nutzung des Bodens und Untergrundes der Tiefsee ein totales rechtliches Vakuum gäbe oder daß die Rechtsordnung Lücken aufweise, die man schließen müsse ${ }^{153}$. Wenn das richtig wäre, würde die Schaffung einer rechtlichen Ordnung für die in Frage stehenden Gebiete angesichts ihrer bevorstehenden Nutzung selbstverständlich dringend erforderlich sein. Hinsichtlich der Auffassung, es bestehe hier ein rechtliches Vakuum, ergeben sich jedoch schon Zweifel bei der Frage, was denn darunter eigentlich zu verstehen ist. Sofern damit gemeint sein sollte, der Boden und Untergrund der Tiefsee bilde eine Art rechtsfreien Raum, würde die Auffassung darauf hinauslaufen, daß die fraglichen Gebiete außerhalb des räumlichen Geltungsbereichs des Völkerrechts lägen. Dieser Bereich erfaßt aber alle Räume, in denen Staaten tätig werden können, also auch den Boden und Untergrund der Tiefsee ${ }^{154}$. Die Regeln des Völkerrechts gelten folg-

152 So Weissberg, a. a. O., S. 100.

153 Vgl. Levy, a. a. O., S. 135; Pardo, Address, S. 224

154 Vgl. Verdross, Alfred: Völkerrecht, 5. Aufl., Wien 1964, S. 225. 
lich auch dort, und von einem rechtsfreien Raum kann nicht die Rede sein. Daher wäre auch zum Beispiel eine etwaige Besetzung bestimmter Teile des Tiefsee-Bodens zum Zwecke der Okkupation an den Regeln des gegenwärtigen Völkerrechts zu messen. Durch die Bezeichnung rechtliches Vakuum könnte aber auch nur ausgedrückt werden sollen, daß die in Frage stehenden Gebiete zwar von dem geltenden Völkerrecht erfaßt seien, dieses aber keine Regeln für die Beurteilung konkreter tatsächlicher Vorgänge auf dem Boden der Tiefsee bereithalte. Dann ist damit nichts anderes gemeint als die angebliche Lückenhaftigkeit des Völkerrechts in diesem Bereich. Auch diese Auffassung ist jedoch falsch. Das Völkerrecht als die das Verhalten von Staaten und sonstigen Völkerrechtssubjekten regelnde Ordnung ist immer in der Lage, die Frage zu beantworten, ob ein bestimmtes Verhalten rechtmäßig ist oder nicht. Wenn das Völkerrecht nämlich einem bestimmten Völkerrechtssubjekt in einer konkreten Situation nicht ein bestimmtes Verhalten vorschreibt, ist dieses in seiner Entscheidung über die zu ergreifenden Maßnahmen frei und jede tatsächlich ergriffene Maßnahme ist rechtmäßig ${ }^{155}$. Auf das bereits genannte Beispiel der Besetzung bestimmter Teile des Tiefsee-Bodens angewandt, würde das bedeuten, daß eine Okkupation dieser Gebiete rechtmäßig ist, sofern nicht das Völkerrecht Normen enthält, die die Okkupation dieser Gebiete verbieten. Eine derartige Verbotsnorm könnte sich wiederum aus dem Prinzip der Freiheit der Meere ergeben oder auch aus den Rechten der Küstenstaaten am Festlandsockel. Zusammenfassend kann man also feststellen, daß in diesem Bereich weder ein rechtliches Vakuum besteht noch die Regeln des Völkerrechts insoweit lückenhaft sind. Allenfalls läßt sich sagen, das Völkerrecht enthalte nur sehr allgemeine Regelungen, deren Anwendung auf bestimmte Sachverhalte oft große Schwierigkeiten bereite oder zu unbefriedigenden Ergebnissen führe.

Während sich die Frage der Lückenhaftigkeit auch in anderen Bereichen des Völkerrechts stellt, handelt es sich bei den folgenden Problemen um solche, die sich erst aus der besonderen Situation der hier behandelten Räume ergeben. Die wichtigste Frage ist die, ob Boden und Untergrund der Tiefsee überhaupt außerhalb der Grenzen nationaler Hoheit liegen. Nur dann kann man ja die Bezeichnung Boden und Untergrund der Tiefsee als einen eigenständigen Rechtsbegriff verwenden. Unter Tiefsee wird hierbei der Teil des Hohen Meeres verstanden, der außerhalb des Kontinentalabfalls (slope) liegt ${ }^{156}$. Die angesprochene Frage wird von den meisten Autoren bejaht ${ }^{157}$, aber unter Berufung auf die Genfer Konvention über den Festlandsockel vom 29. April 1958 auch verneint $^{158}$. Art. 1 der Konvention enthält nämlich eine Legaldefinition des Festlandsockels, die sich mit dem naturwissenschaftlichen Festlandsockelbegriff nicht deckt ${ }^{159}$ und nach ihrem Wortlaut die Inanspruchnahme von Hoheitsrechten auf dem Boden der Tiefsee wohl nicht völlig ausschließt. Denn als Festlandsockel im rechtlichen Sinne wird zwar einerseits nur der Teil des Meeresbodens und -untergrundes behandelt, der außerhalb des Küstenmeeres, aber der Küste benachbart ${ }^{160}$ liegt und bis in eine Wassertiefe von $200 \mathrm{~m}$ reicht. Andererseits

155 So Kelsen-Tucker: Principles of International Law, 2. Aufl., New York/u. a. 1966, S. 438 f.

156 Vgl. Cowen, a. a. O., S. $72 \mathrm{ff}$

157 Vgl. zum Beispiel Young, Richard: The Limits of the Continental Shelf - and beyond, in: Proceedings of the American Society of International Law (1968), S. 229-236 (im folgenden zitiert als Limits); Pardo, Address, S. 227.

$158 \mathrm{Vgl}$. Oda, a. a. O., S. $39 \mathrm{f}$.

159 Vgl. Hoog, a. a. O., S. $48 \mathrm{f}$.

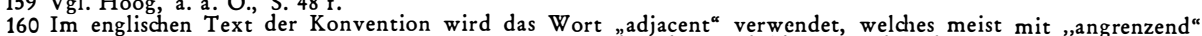
übersetzt wird; vgl. Hoog, a. a. O., S. 111. Angesichts der geschilderten technischen Entwicklung, welche 
enthält Art. 1 aber einen Zusatz, wonach auch tiefer liegende Teile des Meeresbodens und -untergrundes erfaßt werden, soweit eine Ausbeutung der Naturschätze dieser Gebiete möglich ist. Hierdurch wird also die Begriffsbestimmung mehr oder weniger zu einer Funktion der Technik degradiert. Auf diesen Zusatz berufen sich nun einige Autoren und weisen darauf hin, daß die oben geschilderte Entwicklung schon in wenigen Jahren die Ausbeutung des gesamten Meeresbodens ermöglichen werde ${ }^{161}$. Sie folgern daraus, daß dann der gesamte Boden der Tiefsee zum Festlandsockel der Küstenstaaten gehöre und gemäß Art. 6 der Konvention unter diesen aufzuteilen sei.

Diese Auffassung würde in der Praxis zu einer ungerechten Aufteilung der riesigen Gebiete des Tiefsee-Bodens führen. Der Anteil einiger Inseln wäre unverhältnismäßig hoch und andere Staaten - nicht nur Binnenstaaten - würden völlig leer ausgehen. Deshalb versucht ein Teil der Autoren ihr mit einer einengenden Auslegung des Art. $1 \mathrm{zu}$ begegnen. Letztere behaupten daher, das in der Definition des Art. 1 enthaltene Erfordernis der "adjacency“ (Nachbarschaft) sei hinsichtlich der riesigen Gebiete des Tiefsee-Bodens nicht erfüllt und die Auslegung dieser Bestimmung könne sich außerdem nicht völlig von dem mit der Bezeichnung Festlandsockel verbundenen Wortsinn loslösen ${ }^{162}$. Die genannten Einwände gegen eine extensive Auslegung des Art. 1 verdienen Beachtung. Das gilt besonders für den Hinweis auf das Erfordernis der adjacency. Der dahinter stehende Gedanke der Kontiguität wurde ja wiederholt als die innere Rechtfertigung dafür genannt, daß der Festlandsockel den Küstenstaaten zur ausschließlichen Ausbeutung zuzuweisen sei ${ }^{\mathbf{1 6 3}}$.

Logischen Vorrang hat jedoch ein Einwand, der sich aus dem Geltungsbereich der Konvention ergibt. Als Vertragsrecht bindet sie nämlich lediglich die Staaten, die sie ratifiziert haben oder ihr beigetreten sind. Etwas anderes würde sich nur ergeben, wenn der Inhalt der Festlandsockel-Konvention als Gewohnheitsrecht zu betrachten wäre. Das ist jedoch nicht der Fall'164. Zwar kann man angesichts der Tatsache, daß heute die Mehrheit der Staaten unwidersprochen ausschließliche Hoheitsrechte in bezug auf die Erforschung und Ausbeutung der Naturschätze des Festlandsockels in Anspruch nimmt ${ }^{165}$, diese Rechte als Bestandteil des Völkergewohnheitsrechts ansehen. Die Festlandsockel-Konvention des Jahres 1958 hat aber schon ihrem Wortlaut nach nicht geltendes Gewohnheitsrecht kodifiziert, sondern durch Vertrag neues Recht geschaffen ${ }^{166}$. Sie war also bei ihrem Inkrafttreten am 10. Juni 1964 lediglich vertragliches Recht, das nur die Vertragsstaaten band. Daran hat sich in den fünf seither vergangenen Jahren auch nichts geändert, zumal im Jahre 1967 erst 38 Staaten, also noch nicht einmal die Mehrheit der UN-Mitgliedstaaten, die Konvention ratifiziert hatten oder ihr beigetreten waren ${ }^{167}$. Der Inhalt der Festlandsockel-Konvention ist daher, obwohl auch völkerrechtliche Verträge Ansatz einer zur Ausbildung von Gewohnheits-

die Ausbeutung immer größerer Teile des Meeresbodens ermöglicht, gewinnt jedoch eine einschränkende Auslegung Raum, die das in dem Wort adjacent liegende Element der räumlichen Nähe betont, welches besser mit dem Wort benachbart ausgedrückt wird; vgl. Young, Regime, S. 644.

161 Pardo-Gauci weisen auf Schätzungen hin, nach denen bis zum Jahre 1970 bereits 98 Prozent des Meeresbodens zugänglich sein werden; vgl. a. a. O., S. 3.

$162 \mathrm{Vgl}$. zum Beispiel Young, Limits, S. 230. Leyden 1959, S. 132. Wie zweifelhaft diese Rechtfertigung ist, hat Kelsen überzeugend nachgewiesen; vgl. Kelsen, Hans: Contiguity as a title to territorial sovereignty, in: Festschrift für Hans Wehberg, Frankfurt am Main 1956, S. 200-210.

164 A. A. Young, Regime, S. 643 , ohne Begründung.

165 Vgl. zum Stand am 1.6. 1967 Kehden-Henkmann, a. a. O.

166 Vgl. Hoog, a. a. O., S. 47.

167 Vgl. Ago, a. a. O. 
recht führenden Übung sein können, nicht als Ausdruck einer ständigen, einheitlichen und allgemeinen Übung zu betrachten. Es fehlt daher schon an den objektiven Voraussetzungen für die Entstehung eines entsprechenden Gewohnheitsrechts ${ }^{168}$. Eine Prüfung der subjektiven Voraussetzungen und damit auch ein Eingehen auf die Frage, ob das Vorliegen bestimmter subjektiver Voraussetzungen Bedingung für die Entstehung von Gewohnheitsrecht ist ${ }^{169}$, erübrigt sich also. Folglich ist auch die in Art. 1 der Konvention enthaltene Definition des Festlandsockels nicht Bestandteil des Völkergewohnheitsrechts ${ }^{170}$. Aus dieser Bestimmung können daher - unabhängig davon, ob ihr Wortlaut eine entsprechende Auslegung zulassen würde - keine Ansprüche auf Hoheitsrechte am Boden der Tiefsee hergeleitet werden.

Ebensowenig können solche Forderungen mit einer entsprechenden Staatenpraxis begründet werden. Zur Zeit läßt sich noch keine einheitliche und allgemeine Staatenpraxis nachweisen, die die Inanspruchnahme von Teilen des Tiefsee-Bodens unter Berufung auf die Rechte der Küstenstaaten am Festlandsockel zum Inhalt hat. Zwar gibt es Fälle, in denen Küstenstaaten Festlandsockel-Rechte am Boden und Untergrund des Hohen Meeres beanspruchen, die über das Gebiet des Festlandsockels im naturwissenschaftlichen Sinne hinausgehen ${ }^{171}$. Sie sind bislang aber vereinzelt und auch keineswegs einheitlich ${ }^{172}$. Soweit bekannt, üben gegenwärtig außer den Vereinigten Staaten nur Australien, Honduras und Nicaragua solche Hoheitsrechte in Form von Bohrgenehmigungen und Abbaulizenzen aus ${ }^{173}$. Entdeckungen wie die jüngsten Erzfunde im Roten Meer können die Entwicklung allerdings schnell in dieser Richtung vorantreiben ${ }^{174}$. Zur Zeit ist die Staatenpraxis jedenfalls noch insoweit einheitlich, als bisher kein Küstenstaat unter Berufung auf seine Rechte am Festlandsockel Ansprüche auf die riesigen Gebiete unter den Ozeanen geltend gemacht hat. Es gibt folglich Teile des Meeresbodens und -untergrundes, die außerhalb der Grenzen nationaler Hoheit liegen.

Dieser Umstand macht jedoch die Nutzung des Tiefsee-Bodens und -Untergrundes in rechtlicher Hinsicht überhaupt erst so problematisch. Nach der oben abgelehnten Auffassung wäre nämlich „nur“ noch zu klären, wie der Boden der Tiefsee unter die Küstenstaaten aufzuteilen ist, und die Ausbeutung seiner Naturschätze wäre im wesentlichen eine Angelegenheit der innerstaatlichen Rechtsetzung der Küstenstaaten. Nun aber ergeben sich hinsichtlich der in Frage stehenden Räume sehr viel schwierigere Probleme rein völkerrechtlicher Art.

Im Hinblick auf die Tatsache, daß die Ausbeutung des Tiefsee-Bodens sich zunächst wohl auf den am leichtesten zugänglichen Kontinentalabfall konzentrieren wird, ist dabei von größtem praktischen Interesse die Frage nach den Grenzen des Tiefsee-Bodens. Sie ist unter anderem deswegen so schwer zu beantworten, weil an manchen Küsten der Meeresboden sofort in die Tiefe der Ozeane abfällt, ein Festlandsockel im naturwissenschaftlichen Sinne also überhaupt nicht

$168 \mathrm{Zu}$ den Erfordernissen der Bildung von Gewohnheitsrecht nach der Rechtssprechung des Internationalen Gerichtshofes vgl. Böhme, Eckart: Ubber das Gewohnheitsrecht in der Rechtssprechung des Internationalen Gerichtshofes, in: Völkerrecht - Gewohnheitsredit - Naturrecht, Hamburg 1967, S. 91-107.

169 Das wird von der Mehrheit der Autoren bejaht; vgl. Verdross, a. a. O., S. 138.

170 So auch Andrassy, Juraj: Epikontinentalni pojas i medunarodno običajno pravo, in: Medunarodni Problemi 1968 , Nr. 2, S. 29-43. Das Urteil des Internationalen Gerichtshofes im Festlandsockel-Streit zwischen den Niederlanden, Dänemark und der Bundesrepublik Deutschland zu Art. 6 der Konvention, welches dem Verfasser leider noch nicht im Wortlaut vorliegt, scheint die hier vertretene Auffassung ebenfalls zu stützen; vgl. International Herald Tribune vom 21. 2. 1969.

$171 \mathrm{Vgl}$. den Überblick bei Pardo, Seabed, S. 133.

172 Zur Gesetzgebung der Küstenstaaten bis zum 1. 6. 1967 vgl. Kehden-Henkmann, a. a. O.

$173 \mathrm{Zur}$ amerikanischen Praxis vgl. Stone, Oliver L.: United States Legislation relating to the Continental Shelf, in: The International and Comparative Law Quarterly, Bd. 17 (1968), S. $103-117$.

174 Vgl. hierzu Calder, Nigel: Undersea Colonialism, in: New Statesman vom 7. 3. 1969, S. 322-323. 
vorhanden ist. Der Boden der Tiefsee ist daher nicht nur gegen den Festlandsockel, sondern auch gegen das Küstenmeer abzugrenzen. Die völkerrechtlich zulässige Ausdehnung des Küstenmeeres und die Abgrenzung des Festlandsockels sind jedoch heftig umstritten. Beide Probleme wären eine eingehende Untersuchung wert, welche jedoch den Rahmen dieser Ausführungen erheblich überschreiten würde. Es muß daher hinsichtlich der Grenze zum Küstenmeer mit dem Hinweis sein Bewenden haben, daß einerseits auf den Genfer Seerechtskonferenzen eine Einigung über die Breite des Küstenmeeres nicht erzielt werden konnte, andererseits die größten bis jetzt geltend gemachten Ansprüche ein Küstenmeer von $200 \mathrm{sm}$ Breite beinhalten ${ }^{175}$. Unterstellt man einmal die Rechtmäßigkeit derart weitgehender Ansprüche, so ergibt sich daraus, daß die Grenze des Tiefsee-Bodens zum Küstenmeer in einer Entfernung von höchstens $200 \mathrm{sm}$ von der Küstenlinie verläuft.

In bezug auf die Grenze zum Festlandsockel wurden die Schwierigkeiten, die sich aus der Abgrenzung des Festlandsockels ergeben, bereits angedeutet. Es sei daher hier lediglich die Frage aufgeworfen, ob die Gründe, die zur Loslösung des rechtlichen Festlandsockelbegriffs vom naturwissenschaftlichen geführt haben, nämlich das Bestreben, eine klare Grenze zum übrigen Boden des Hohen Meeres zu ziehen ${ }^{176}$, heute noch durchgreifen. Konnte man nämlich in den fünfziger Jahren angesichts der mangelnden Erforschung des Meeresbodens auf die Schwierigkeiten der Bestimmbarkeit des Festlandsockels im naturwissenschaftlichen Sinne hinweisen ${ }^{177}$, so könnten die seitdem zu verzeichnenden rapiden Fortschritte von Meeresforschung und -technik diese Schwierigkeiten unter Umständen verringert haben. Gleichzeitig hat das Kriterium der Ausbeutungsmöglichkeit durch die nämliche Entwicklung seine Eignung zur Grenzziehung erheblich eingebüßt und wird sie in den nächsten Jahren wahrscheinlich sogar völlig verlieren. Daher könnte sich eine Annäherung des rechtlichen an den naturwissenschaftlichen Festlandsockelbegriff nunmehr selbst aus praktischen Gründen als wünschenswert erweisen. In diesem Sinne ist auch die einschränkende Auslegung des Art. 1 der Festlandsockel-Konvention zu unterstützen, die betont, daß seine Auslegung nicht zu einer Lösung des Festlandsockel-Begriffes von dem damit verbundenen Wortsinn führen dürfe ${ }^{178}$. Beruht doch der Wortsinn auf dem Naturphänomen Festlandsockel, d. h. der Fortsetzung der Festlandmassen unter der Meeresoberfläche bis zu ihrem Abfall in die Tiefe der Ozeane. Zur Abweisung übertriebener Ansprüche auf Festlandsockel-Rechte erscheint dieser Weg jedenfalls erfolgversprechender als die Betonung des Erfordernisses der adjacency. Selbst der Festlandsockel im naturwissenschaftlichen Sinne ist nämlich an manchen Stellen so ausgedehnt, daß man dort von adjacency nur im Sinne von angrenzend sprechen kann. Unter diesem Gesichtspunkt könnten daher keine Einwendungen gegen die Aufteilung des Bodens und Untergrundes tiefer Randmeere wie etwa des Mittelmeeres, des Golfes von Mexico oder der Karibischen See erhoben werden. Schon diese Beispiele zeigen, daß - sofern auch heute noch der naturwissenschaftliche Festlandsockelbegriff kein geeignetes Abgrenzungskriterium bilden sollte - wenigstens eine genauere Definition des Festlandsockels im juristischen Sinne erforderlich ist.

\footnotetext{
175 Vgl. Kehden-Henkmann, a. a. O.

176 Nach Kunz soll sich der juristische von dem naturwissenschaftlichen Festlandsockelbegriff allerdings nur dadurch unterscheiden, daß der juristische den Boden und Untergrund des Küstenmeeres nicht mit umfaßt; vgl. a. a. O., S. 518. An dieser Unterscheidung ist natürlich festzuhalten.

177 Vgl. Mouton, a. a. O., S. $39 \mathrm{ff}$.

178 Vgl. Young, Limits, S. 230.
} 
Ein Problem von zur Zeit noch mehr theoretischer Bedeutung, das aber auf lange Sicht darüber hinaus auch von größter praktischer Bedeutung sein wird, ist das des gegenwärtigen Rechtsstatus dieser Räume ${ }^{179}$. Von seiner Lösung hängt nämlich die Antwort auf die weitere Frage ab, ob Boden und Untergrund der Tiefsee von einzelnen Staaten okkupiert werden können oder nicht. Letzteres wäre $\mathrm{zu}$ verneinen, wenn sie wie das Hohe Meer als res communis omnium zu betrachten wären. Viele Autoren sehen sie jedoch als Land unter Wasser und damit als res nullius an. Sie machen daher ihre Okkupierbarkeit allein von den Möglichkeiten einer effektiven Herrschaftsübung abhängig ${ }^{130}$. $\mathrm{Daß}$ diese Möglichkeiten hinsichtlich einiger Erhebungen des Tiefsee-Bodens schon in der Gegenwart bestehen, wurde bereits ausgeführt. Es fehlen aber vertragliche Regelungen oder - mit Ausnahme einiger Sonderfälle, die nicht verallgemeinert werden können ${ }^{181}$ - eine entsprechende Staatenpraxis, die diese Auffassung auch rechtlich stützen würden. Soweit ersichtlich, hat bisher lediglich Großbritannien bestimmte Teile des Bodens des Hohen Meeres ausdrücklich annektiert, diese Praxis jedoch nach Durchsetzung der Festlandsockel-Theorie wieder aufgegeben ${ }^{132}$. Die Praxis einiger lateinamerikanischer Staaten, die durch übermäßige Ausweitung ihres Küstenmeeres das Fehlen eines Festlandsockels in naturwissenschaftlichen Sinne zu kompensieren versuchen, kann in diesem Zusammenhang nicht berücksichtigt werden. Es handelt sich dabei nämlich nicht um Okkupationen im Rechtssinne. Außerdem stößt die Praxis auf heftige Proteste anderer Länder, vor allem aber der Vereinigten Staaten ${ }^{183}$. Umgekehrt lehnen einige lateinamerikanische Staaten das Prinzip der horizontalen Begrenzung der Souveränität, auf welches sich einige Autoren zur Rechtfertigung einer Okkupierbarkeit des Meeresbodens berufen haben, ausdrücklich ab. Im Gegenteil beanspruchen sie unter Berufung auf das Prinzip der horizontalen Einheit der Souveränität sogar das epikontinentale Meer ${ }^{184}$. Der letztgenannte Grundsatz kann allerdings nicht zur Rechtfertigung von Ansprüchen auf die über dem Festlandsockel liegende Wassersäule herangezogen werden. Bei den Rechten der Küstenstaaten am Festlandsockel handelt es sich nicht um Gebietshoheit, sondern um zahlenmäßig und inhaltlich beschränkte Hoheitsrechte, die eine Zurechnung des Festlandsockels zum Staatsgebiet der Küstenstaaten nicht zulassen ${ }^{185}$. Zwar scheint sich hier gegenwärtig eine Bewußtseinsänderung zu vollziehen, die auf die Dauer wohl auch nicht ohne Folgen für den Rechtsstatus des Festlandsockels und selbst des epikontinentalen Meeres bleiben wird ${ }^{186}$. Im gegenwärtigen Zeitpunkt ist der Rechtsstatus des Festlandsockels aber eher mit demjenigen der Anschlußzone zu vergleichen, die - anders als das Küstenmeer ${ }^{187}$ - ebenfalls nicht zum Staatsgebiet $\mathrm{zu}$ rechnen ist ${ }^{185}$.

179 Vgl. hierzu Heidelmeyer, Wolfgang: Meeresgrund, in: Strupp-Schlochauer: Wörterbuch des Völkerrechts,

180 So zum Beispiel Kelsen, a. a. O., S. 200; Verdross, a. a. O., S. 280; Young, Regime, S. 645; vgl. auch die bei Heidelmeyer, a. a. O., S. 496, genannten Autoren.

$181 \mathrm{Vgl}$. dazu die bei Colombos genannten Fälle, in denen bestimmte ausschließliche Nutzungsrechte an begrenzten Teilen des Bodens des Hohen Meeres anerkannt wurden, jedoch keine volle Gebietshoheit: Colombos, C. John: The Internationale Law of the Sea, 6. Aufl., London 1967, S. 67. Zum Ausnahmecharakter dieser Rechte vgl. auch Böhmert, Viktor: Grundfischerei, in: Strupp-Schlochauer: Wörterbuch des Völkerrechts, 2. Aufl., Bd. 1, Berlin 1960, S. 717-720. Im folgenden zitiert als Grundfischerei.

$182 \mathrm{Vgl}$. Menzel, Eberhard: Der deutsche Festlandsockel in der Nordsee und seine rechtliche Ordnung, in: Archiv des öffentlichen Rechts, Bd. 90 (1965), S. 1-61 (30, 35).

183 Vgl. Kunz, a. a. O., S. $517 \mathrm{f}$.

184 Vgl. Kunz, a. a. O., S. 519.

185 Vgl. Menzel, a. a. Ö., S. 36

186 Das offenbaren besonders die Außerungen, die die Anerkennung der Festlandsockel-Rechte in erster Linie unter dem Gesichtspunkt des Gebietszuwachses sehen. Bezeichnend ist in diesem Zusammenhang die Bemerkung von Hersh (a. a. O., S. 8): "In June, 1964, the United States, simply by ratifying a treaty agreement, gained more land for exploitation than ever before in its history. All of the $n$ e $w$ t $\mathrm{er} i \mathrm{i}$ tory, an area larger than the original 13 colonies and the Louisiana Purchase, is under water." 187 Dessen 'Zugehörigkeit zum Staatsgebiet ist heute allgemein anerkannt; vgl. zum Beispiel Münch, Fritz: 
Die entscheidende Frage für die Lösung des Problems dürfte die sein, ob das Prinzip der Freiheit der Meere auch für den Boden und Untergrund der Tiefsee gilt. Sie kann jedoch im Rahmen dieser Erörterungen nicht definitiv beantwortet werden, da hierzu eine eingehende Prüfung erforderlich wäre. Daher soll lediglich auf zwei Gesichtspunkte hingewiesen werden, die für eine Erstrekkung der Meeresfreiheit sowohl auf den Boden als auch auf den Untergrund der Tiefsee sprechen. Der erste, welcher die breitere Anerkennung erfahren hat, ergibt sich aus der Freiheit der Meere selbst ${ }^{183}$. Er beruht auf der Erwägung, daß dieses Prinzip gefährdet wäre, wenn eine Okkupation des Bodens des Hohen Meeres zulässig wäre ${ }^{189}$. Da die Herrschaft über den Meeresboden zwangsläufig die Beherrschung des Hohen Meeres selbst zur Folge haben würde und der Rechtsstatus des Hohen Meeres letzteres verbietet, hat nach dieser Auffassung der Boden des Hohen Meeres den gleichen Rechtsstatus wie dieses selbst ${ }^{190}$. Die Befürworter dieser Argumentation halten jedoch umgekehrt mit der Begründung, daß eine Herrschaft über den Untergrund des Hohen Meeres keine solchen Gefahren für den Rechtsstatus des Hohen Meeres mit sich bringe, eine Okkupation des Meeresuntergrundes zum Teil für zulässig ${ }^{191}$. Zur Begründung dieser Ansicht werden aber als Beispiele für eine Herrschaft über den Meeresuntergrund nur unterseeische Tunnel und Bergwerksstollen, die vom Festland eines Küstenstaates aus in den Untergrund des Hohen Meeres getrieben werden ${ }^{192}$, genannt. Das läßt vermuten, andere Formen der Nutzung des Meeresuntergrundes, die vom Hohen Meer aus erfolgen werden, seien nicht berücksichtigt worden. Es ist daher darauf hinzuweisen, daß anders als beim Festlandsockel, der sowohl horizontal vom Festland als auch vertikal vom Hohen Meer aus genutzt wird, die Nutzung des Untergrundes der Tiefsee wahrscheinlich nur vom Hohen Meer aus erfolgen wird. Ausgangspunkt dieser Nutzungen werden vermutlich Installationen auf dem Boden der Tiefsee sein, die auf die Dauer eine unterschiedliche Behandlung von Boden und Untergrund der Tiefsee unmöglich machen werden. Das drastischste Beispiel hierfür liefern unterseeische Raketenabschußbasen, deren Raketen auf Seeziele gerichtet sind. Je tiefer sie in den Untergrund des Hohen Meeres eingelassen sind, desto gefährlicher sind sie für die Schiffahrt; denn um so schwerer können sie entdeckt und ausgeschaltet werden. Generell läßt sich sagen, daß der Staat, der über bestimmte Teile des Meeresuntergrundes herrschen wird, auch die entsprechende Fläche des Meeresbodens beherrschen und danach streben wird, die dort vorhandenen Einrichtungen durch Inanspruchnahme von Sonderrechten an der darüber liegenden Wassersäule zusätzlich zu sichern. Das gilt besonders für Installationen militärischer Art, da hier die Gefahr von Spionage und Sabotage besteht. Es ist also zu befürchten, daß die Anerkennung von Hoheitsrechten am Untergrund der Tiefsee auf die Dauer die Freiheit der Meere ebenfalls beeinträchtigen wird.

Der zweite Gesichtspunkt für eine Erstreckung der Freiheit der Meere auf den Boden und Untergrund der Tiefsee ist das Prinzip der vertikalen Einheit des Raumes ${ }^{193}$. So wie die Abgrenzung des Staatsgebietes vertikal erfolgt und des-

Küstengewässer, in: Strupp-Schlochauer: Wörterbuch des Völkerrechts, 2. Aufl., Bd. 2, Berlin 1961, Seite 388-391 (390 f.); Böhmert, Victor: Natur und Umfang der der Bundesrepublik Deutschland am Kontinentalschelf zustehenden Rechte, in: Internationales Recht und Diplomatie 1967, S. 101-129 (101). Im folgenden zitiert als Kontinentalschelf.

188 Vgl. außer Böhmert, Meeresfreiheit, S. 83, auch Colombos, a. a. O., S. 67, und Krüger, a. a. O., S. 791.

189 So Colombos, a. a. O., S. 67; Krüger, a. a. O., S. 791.

190 Vgl. Krüger, a. a. O., S. 791.

191 So Colombos, a. a. O., S. 69; Krüger; a. a. O., S. 791.

192 Vgl. Colombos, a. a. O., S. 69.

193 Dieses wird besonders von Böhmert betont; vgl. Kontinentalschelf, S. 102; Meeresfreiheit, S. 83. Aber auch einige lateinamerikanische Staaten berufen sich - allerdings mit umgekehrtem Vorzeichen, nämlidh 
halb die Räume unterhalb der Erdoberfläche genauso erfaßt wie den darüber liegenden Luftraum ${ }^{194}$, ist danach auch der Bereich des Hohen Meeres vertikal abzugrenzen. Er erstreckt sich folglich auch auf den Luftraum über sowie den Boden und Untergrund unter dem Hohen Meer. Die Verbindlichkeit dieses Prinzips für die Abgrenzung der Landfläche des Hoheitsgebietes der Staaten ist allgemein anerkannt ${ }^{195}$, desgleichen für die Abgrenzung des Küstenmeeres ${ }^{196}$. In bezug auf den Boden und Untergrund des Hohen Meeres wird von vielen Autoren jedoch das Prinzip der horizontalen Delimitierung der Souveränität vertreten ${ }^{197}$. Es dürfte aber richtiger sein, auch den Bereich des Hohen Meeres als eine rechtliche Einheit zu betrachten. Hierbei bleibt es im Ergebnis gleich, ob man das Prinzip der vertikalen Abgrenzung oder horizontalen Unteilbarkeit des Staatsgebietes analog auf das Hohe Meer anwendet ${ }^{198}$ oder letzteres unabhängig davon als einen einheitlichen internationalen Raum ansieht ${ }^{199}$. Für eine einheitliche Behandlung spricht unter anderem, daß Art. 2 der Genfer Konvention über das Hohe Meer vom 29. April 1958, die als Kodifikation bestehenden Völkergewohnheitsrechts $\mathrm{zu}$ qualifizieren ist ${ }^{200}$, außer den Freiheiten der Schiffahrt und der Fischerei auf dem Hohen Meer auch die nennt, es zu überfliegen und auf seinem Boden Kabel und Rohrleitungen zu verlegen. Art. 2 wiederum entspricht im wesentlichen dem Art. 27 des Konventions-Entwurfes, den im Jahre 1956 die International Law Commission der Vereinten Nationen vorgelegt hat. Und zwar ist hierzu mit Böhmert ${ }^{201}$ darauf hinzuweisen, daß diese in Art. 27 die von ihr als selbstverständlich vorausgesetzte Freiheit der Erforschung und Ausbeutung des Untergrundes des Hohen Meeres nur deshalb nicht aufnahm, weil sie damals noch keine hinreichende praktische Bedeutung erlangt hatte ${ }^{202}$. Darüber hinaus ist dem zweiten Absatz des Art. 2 zu entnehmen, daß die Aufzählung der Freiheiten im ersten Absatz nur beispielhaft ist. Denn dort heißt es ${ }^{203}$ :

„Diese sowie die anderen nach den allgemeinen Grundsätzen des Völkerrechts anerkannten Freiheiten sind von jedem Staat unter angemessener Berücksichtigung der Interessen auszuüben, die andere Staaten am Gebrauch der Freiheit des Hohen Meeres haben."

Art. 2 bestimmt also generell, daß die Freiheit der Meere auch für den über dem Hohen Meer liegenden Luftraum und den darunter liegenden Teil der Erdkruste gilt. Daraus läßt sich weiter ableiten, daß der gesamte ozeanische Raum $^{204}$ rechtlich eine Einheit bildet und der Boden und Untergrund des Hohen Meeres somit wie das Hohe Meer selbst als res communis omnium im Gemeingebrauch aller Nationen stehen. Sie sind folglich einer Okkupation - unabhängig von der tatsächlichen Möglichkeit einer effektiven Besetzung - entzogen, weil eine solche andere Staaten von dem Gemeingebrauch an den okkupierten Gebieten

zur Rechtfertigung ihrer Ansprüche auf das epikontinentale Meer - auf dieses Prinzip; vgl. Kunz, a. a. O., S. 519 .

194 Vgl. Ridder, Helmut: Gebietshoheit, in: Strupp-Schlochauer: Wörterbuch des Völkerrechts, 2. Aufl., Bd. 1, Berlin 1960, S. 624-629 (625).

195 Vgl. Ridder, a. a. O., S. 625 f., Verdross, a. a. O., S. 271

196 Der Grund hierfür liegt jedoch in seiner Zugehörigkeit zum Staatsgebiet; vgl. Münch, a. a. O., S. 390 f.

197 Vgl. auch die bei Kunz (a. a. O., S. 519 f.) genannten Autoren.

198 So anscheinend Heidelmeyer, a. a. O., S. $495 \mathrm{f}$

199 So Böhmert, Kontinentalschelf, S. $102 \mathrm{f}$.

200 Vgl. Hoog, a. a. O., S. 31.

201 Kontinentalschelf, S. 103.

202 Vgl. Yearbook of the International Law Commission 1956, Bd. 2, S. 278.

203 Deutscher Text: Hoog, a. a. O., S. 79.

204 Die Bezeichnung „ozeanischer Raum “ wird sogar von den Befürwortern einer Okkupierbarkeit des Meeres-

bodens und -untergrundes verwendet, ohne daß daraus aber rechtliche Konsequenzen gezogen werden; vgl. Young, Regime, S. 641. Merkwürdigerweise soll sie den Luftraum über dem Hohen Meer nicht mit umfassen. 
ausschließen würde ${ }^{205}$. Die Staaten können daher nur in besonders gelagerten Fällen in diesem Raum einzelne Sonderrechte beanspruchen wie zum Beispiel Polizeirechte in der Anschlußzone oder Erforschungs- und Ausbeutungsrechte im Bereich des Festlandsockels. Da sich die Festlandsockelrechte aber - wie ausgeführt wurde - nicht auf den Boden und Untergrund der Tiefsee erstrecken, steht die Nutzung dieser Gebiete allen Nationen offen ${ }^{206}$.

Mit der Qualifikation des Bodens und Untergrundes der Tiefsee als res communis omnium, die im Gemeingebrauch aller Nationen stehen, vermehren sich die Probleme jedoch eher noch, als daß sie sich verringern. Die sich daraus ergebende Unmöglichkeit einer Okkupation entzieht nämlich die in Frage stehenden Räume dem einzigen wirksamen Ordnungsfaktor, den es nach dem augenblicklichen Stand der Dinge gibt: der Hoheitsgewalt der Nationalstaaten. Die statt dessen bestehende Ordnung des Gemeingebrauches aller Nationen wird sich aber in ihrer gegenwärtigen Gestalt auf die Dauer wohl kaum als angemessene Regelung der in Frage kommenden Nutzungen erweisen. Handelt es sich doch dabei entsprechend der Terminologie des deutschen öffentlichen Sachenrechts zum größten Teil um Sondernutzungen. Diese erfordern aber auch eine rechtliche Ordnung, die dem Unterschied zwischen Gemeingebrauch und Sondernutzung sowie dem zwischen den unterschiedlichen Arten der Sondernutzung durch eine entsprechende Differenzierung Rechnung trägt.

Diese Besonderheiten der Nutzung des Tiefsee-Bodens und -Untergrundes erklären sich wie folgt: Die Nutzungen des Hohen Meeres und des darüber liegenden Luftraumes - zum Beispiel das Befahren mit Schiffen, das Fischen und das Überfliegen - tragen normalerweise den Charakter des Vorübergehenden und Zeitgebundenen. Demgegenüber werden sich die Nutzungen des Bodens und vor allem des Untergrundes der Tiefsee überwiegend durch die Wesensmerkmale der Dauer und der Ortsgebundenheit auszeichnen. Die überkommenen Nutzungen des Hohen Meeres und seines Luftraumes stellen - ähnlich solchen Nutzungen öffentlicher Flächen im innerstaatlichen Bereich wie etwa der Teilnahme am StraBenverkehr - den Gemeingebrauch anderer nur in Ausnahmesituationen, zum Beispiel an besonders verkehrsreichen Stellen, in Frage. Dagegen werden die wichtigsten Nutzungen des Tiefsee-Bodens und -Untergrundes in der Regel den Charakter besonderer Inanspruchnahme der genutzten Räume und die Tendenz zur Ausschließung des Gemeingebrauches anderer auf weisen ${ }^{207}$.

Das gilt in geringem Maße schon für das Verlegen unterseeischer Kabel und Rohrleitungen auf dem Meeresboden. In ihrer unmittelbaren Nähe sind andere Nutzungen nur in begrenztem Umfang oder gar nicht möglich. Das gilt noch mehr für die Lagerung von radioaktiven Abfällen und anderen schädlichen Stoffen. Da die Möglichkeit einer Verseuchung der Lagerstätten besteht, lassen die hiermit verbundenen Gefahren auf lange Zeit die Einhaltung eines größeren Sicherheitsabstandes bei anderen Nutzungen geboten erscheinen. Das gilt aber ganz besonders - vor allem aus wirtschaftlichen Erwägungen - auch für die

$205 \mathrm{Daß}$ das Hohe Meer im Gemeingebrauch aller steht und aus diesem rechtlichen Grunde, nicht wegen seiner mangelnden Bestimmbarkeit und Beherrschbarkeit, nicht der Souveränität einzelner Staaten unterstellt werden kann, ist heute unbestritten; vgl. Krüger, a. a. O., S. 791. Diese Vorstellung hat auch in Art. 2 der Konvention über das Hohe Meer ihren Niederschlag gefunden; vgl. Hoog, a. a. O., S. $31,79$.

206 Eine Ausnahme gilt lediglich für bestimmte, historisch gewachsene ausschließliche Nutzungsrechte im Bereich der Grundfischerei. Diese finden ihre Rechtfertigung jedoch darin, daß bestimmte Stellen des Bereich der Grundfischerei. Diese finden ihre Rechtfertigung jedoch darin, daß bestimmte Stellen des
Meeresbodens lange Zeit hindurch von den Angehörigen einer Nation genutzt und gepflegt wurden und diese Kultivierung des Meeresbodens die Grundlage für die heutige Nutzung bildet; vgl. Böhmert, Grundfischerei, S. 718.

$207 \mathrm{Für}$ militärische Installationen gilt das wegen der Erfordernisse der Geheimhaltung und der Verhinderung von Sabotage in noch viel größerem Maße. 
Ausbeutung der Naturschätze des Tiefsee-Bodens und -Untergrundes. Letztere wird nämlich bereits im Erschließungs-Stadium, und zwar in noch viel größerem Maße als die schon sehr kostspielige Ausbeutung des Festlandsockels, außerordentlich hohe Investitionen für Probebohrungen, Installationen auf dem Tiefsee-Boden, hochseefähige Transportmittel und vieles andere mehr erfordern. Solche Ausgaben können aber sowohl private als auch staatliche Unternehmen nur verantworten, wenn sie sicher sind, daß ihnen auch die ausschließliche Nutzung der dabei entdeckten Vorkommen zusteht ${ }^{208}$. Diese ortsgebundenen Aufwendungen, die es bei der Nutzung des Luftraumes und der Wassersäule des Hohen Meeres nicht oder nur in unbedeutendem Umfang gibt, werden daher entsprechende Sicherheiten in Gestalt von ebenfalls ortsgebundenen ausschließlichen Sonderrechten für den erfordern, der ein bestimmtes Feld mit hohen Kosten für die Ausbeutung vorbereitet.

Die gegenwärtige Ordnung des Gemeingebrauches aller wird den genannten besonderen Gegebenheiten jedoch insofern nicht gerecht, als die einzige Schranke, die sie für die Nutzung enthält, nämlich der Gemeingebrauch anderer, auf die Dauer nicht ausreichen wird, um Konflikte zu vermeiden. Solche werden sich aber - vor allem bei der Ausbeutung von Gebieten mit besonders wertvollen Vorkommen - wahrscheinlich aus dem wesensnotwendig ausschließlichen Charakter der wichtigsten Nutzungen ergeben. Eine Ausnahme könnte lediglich die Ausbeutung der erwähnten riesigen nodule-Felder bilden, weil sich dort Möglichkeiten abzeichnen, die eine ortsgebundene Inanspruchnahme entbehrlich zu machen scheinen ${ }^{209}$. Damit kann die Ausgangsfrage der Erörterungen, nämlich die Frage nach der Reformbedürftigkeit der Normen betreffend die Nutzung des Bodens und Untergrundes der Tiefsee, eindeutig bejaht werden.

Es stellt sich dann die weitere Frage nach der inhaltlichen Ausgestaltung einer zukünftigen Regelung. In der bisherigen Diskussion über diese Frage sind abgesehen von dem "wait and see“ approach, der darauf hinausläuft, abzuwarten und die Dinge sich erst einmal entwickeln zu lassen - bisher drei Grundhaltungen sichtbar geworden ${ }^{210}$. Die erste läuft auf eine Aufteilung des TiefseeBodens unter die Küstenstaaten nach dem Vorbild der Festlandsockel-Theorie hinaus und ist unter der Bezeichnung "national lake" approach bekannt geworden. Hierzu soll an dieser Stelle lediglich darauf hingewiesen werden, daß die Gründe, die zur Anerkennung der Festlandsockel-Rechte geführt haben - sofern man sie wenigstens dort als berechtigt anerkennt ${ }^{211}$ - hinsichtlich des Bodens der Tiefsee mangels besonderer räumlicher Beziehung mit Ausnahme weniger Fälle nicht eingreifen. Den Ausnahmefällen könnte man aber durch eine entsprechende Ausdehnung des Küstenmeeres besser gerecht werden. Diese ist auf die Dauer wohl sowieso nicht zu verhindern. Sie müßte aber nach dem Vorbild einiger lateinamerikanischer Staaten die Freiheit der Schiffahrt unangetastet lassen. Außerdem würden durch eine Aufteilung des Tiefsee-Bodens nach dem Festlandsockel-Prinzip sämtliche Binnenstaaten und die Küstenstaaten vieler Randmeere - Nord- und Ostsee, Mittelmeer, Schwarzes Meer, Rotes Meer, Persischer Golf, Südchinesisches Meer - von der Nutzung des Bodens der Ozeane völlig ausgeschlossen werden.

208 Pardo weist in diesem Zusammenhang darauf hin, daß das Fehlen einer Regelung - richtiger einer befriedigenden Regelung - sich bereits verzögernd auf die Ausbeutung des Tiefsee-Bodens auswirkt, weil den Unternehmen entsprechende Investitionen zu riskant sind; vgl. Address, S. 224.

209 Das wäre der Fall, wenn sich Förderverfahren wie die von John Mero vorgeschlagene Methode des Absaugens des Tiefseebodens mit einer Art Saugbagger realisieren ließen; vgl. Cowen, a. a. O., S. $264 \mathrm{ff}$. 210 Vgl. hierzu Pardo, Address, S. $223 \mathrm{ff}$. 211 Vgl. Kelsen, a. a. O. 
Eine zweite, als "flag nation" approach gekennzeichnete Haltung will die Naturschätze des Tiefsee-Bodens und -Untergrundes dem Flaggenrecht des Staates unterstellen, von dessen Angehörigen die Vorkommen jeweils entdeckt und ausgebeutet werden. Dieses Konzept kommt den Interessen der Industrienationen am meisten entgegen, weil es ihnen die größte Handlungsfreiheit gewährt. Rechtlich würde eine derartige Regelung keinen Staat von der Nutzung der fraglichen Gebiete ausschließen. In der Praxis würden allerdings der enorme Kapitalbedarf und die zur Ausbeutung des Tiefsee-Bodens erforderliche Technologie die meisten kleinen Nationen an einer Nutzung hindern. Etwas anderes würde sich lediglich dann ergeben, wenn sie ihre finanziellen und technischen Möglichkeiten durch Zusammenschlüsse - etwa im Rahmen der bestehenden Wirtschaftsgemeinschaften - erweitern würden. Gegenüber dem gegenwärtigen Rechtszustand stellt dieses Konzept kaum eine Verbesserung dar; denn es ist genau wie dieser nicht geeignet, die bestehenden Konfliktsmöglichkeiten zu beseitigen $^{212}$. Außerdem könnte sich eine derartige Regelung unter Umständen lediglich als Vorstufe für die Okkupation bestimmter Gebiete erweisen ${ }^{213}$.

Als letztes sind schließlich die bereits genannten Bestrebungen $\mathrm{zu}$ nennen, die den Boden und Untergrund der Tiefsee unter eine internationale Verwaltung stellen wollen. Eine auf diesem „international regime“ approach beruhende Regelung würde im Idealfall den freien Zugang zu den einzelnen Nutzungen aufrechterhalten, eine gerechte Verteilung der Erlöse sichern sowie Vorsorge zur Abwendung negativer Auswirkungen treffen. Dadurch würde sie die Nachteile der zuvor genannten Modelle für eine zukünftige Regelung und des jetzigen Rechtszustandes ausschalten und ihre Vorteile in sich vereinen. Darüber hinaus könnte sie die Zusammenarbeit der Völker in ein völlig neues Stadium rücken. Man muß aber angesichts der Tatsache, daß generell das Zustandekommen und die Arbeit zwischenstaatlicher Organisationen mit unendlichen Schwierigkeiten verbunden ist, bezweifeln, ob sich ein solches Konzept in naher Zukunft verwirklichen läßt. Hierfür genügt es nämlich nicht, daß die Staaten davon überzeugt werden können, es würde letzten Endes auch ihren nationalen Interessen am weitesten entgegenkommen. Erforderlich ist vielmehr ein Geist der $\mathrm{Zu}$ sammenarbeit, der selbst bei manchen Befürwortern dieses Konzepts zu vermissen ist. Betrachten doch einige eine internationale Verwaltung anscheinend vor allem als Vehikel für die Durchsetzung rein nationaler Interessen.

Das Für und Wider der genannten Grundhaltungen kann hier nicht in extenso erörtert werden. Es ist auch fraglich, ob ein Vergleich ihrer Vor- und Nachteile einen fruchtbaren Ausgangspunkt für die erforderlichen Überlegungen bildet. Er fixiert nämlich die Gedanken zu sehr auf den - allerdings menschlich verständlichen - Gesichtspunkt, wie die Naturschätze der Tiefsee unter die Nationen $\mathrm{zu}$ verteilen sind. Eine solche Betrachtungsweise führt aber von der Sache weg und berücksichtigt zu wenig, daß eine zukünftige Regelung lediglich dann eine Verbesserung gegenüber der gegenwärtigen darstellt, wenn sie unter Beibehaltung ihrer Vorteile deren Nachteile beseitigt. Nur dann ist sie überhaupt erstrebenswert. Welches aber die objektiven Kriterien einer optimalen Regelung sind, kann zur Zeit wohl noch niemand abschließend beurteilen. Unser Wissen

212 Es würde auch viele Probleme ungelöst lassen und darüber hinaus schwierige flaggenrechtliche Probleme - vor allem das der billigen Flaggen - auch für die Nutzung des Tiefseebodens relevant werden lassen; vgl. hierzu Young, Regime, S. 646.

213 Diese Gefahr besteht besonders deshalb, weil schon die Unterstellung unter das Flaggenrecht des ausbeutenden Staates juristisch eine beschränkte Okkupation beinhaltet. 
über den Boden und Untergrund der Tiefsee ist wahrscheinlich noch viel zu gering, um die Möglichkeiten und Gefahren ihrer Nutzung bereits hinreichend abschätzen zu können. Es ist also zunächst einmal eine umfassende Bestandsaufnahme hinsichtlich des gegenwärtigen Wissens über diese Gebiete, über die Möglichkeiten ihrer friedlichen und militärischen Nutzung sowie die wirtschaftlichen und sonstigen Auswirkungen dieser Nutzungen, insbesondere die möglichen Rückwirkungen auf andere Formen der Nutzung des ozeanischen Raumes ${ }^{214}$ erforderlich. Hierbei haben die bisherigen Bemühungen der Vereinten Nationen bereits wertvolle Arbeit geleistet und werden das auch in Zukunft können. Außerdem ist eine Intensivierung der Meeresforschung erforderlich, bei der die Vereinten Nationen ebenfalls nützliche Dienste leisten können, indem sie durch Förderung weltweiter Forschungsprogramme und Koordinierung nationaler Projekte die Vermehrung des erforderlichen Wissens beschleunigen und $\mathrm{zu}$ seiner Verbreitung beitragen ${ }^{215}$.

Hinsichtlich der rechtlichen Vorarbeiten für eine zukünftige Regelung erscheint eine Einschaltung der Vereinten Nationen schon wegen ihrer großen Mitgliederzahl216 ebenfalls wünschenswert. Da bei den Genfer Seerechtskonferenzen und den Beratungen des maltesischen Vorschlages erhebliche Meinungsverschiedenheiten über grundlegende Fragen des geltenden internationalen öffentlichen Seerechts zu Tage getreten sind, die auch für die Rechtsordnung des Tiefsee-Bodens und -Untergrundes von entscheidender Bedeutung sind, wäre es allerdings am zweckmäßigsten, wenn zunächst diese Fragen geklärt werden würden ${ }^{217}$. Hier würde sich der kürzlich eingesetzte Ausschuß für die friedliche Nutzung des Meeresbodens große Verdienste erwerben, wenn es ihm gelänge, die bestehende Rechtsunsicherheit zu beheben ${ }^{218}$. Außerdem könnten die Vereinten Nationen bei der Herausarbeitung einer zukünftigen Regelung als das Forum dienen, in dem sich der hierzu erforderliche Prozeß der Angleichung der Auffassungen und Herausbildung einer einheitlichen Meinung vollzieht. Da hier aber über den Rechtsstatus von Räumen entschieden werden muß, die fast dreimal so groß sind wie das Hoheitsgebiet sämtlicher Staaten der Erde zusammen, dürfte dieser Prozeß sofern es überhaupt zu einer Einigung kommt - sehr langwierig sein.

Welche Rolle die Vereinten Nationen in einer zukünftigen Rechtsordnung des Tiefsee-Bodens und -Untergrundes selbst spielen sollten, hängst zunächst einmal von den Ergebnissen $a b$, zu denen die genannten Vorarbeiten führen werden. Weiter ist hierfür von Bedeutung, ob es möglich sein wird, in den Vereinten Nationen die organisatorischen Voraussetzungen zu schaffen, welche eine möglicherweise als wünschenswert erscheinende internationale Verwaltung der fraglichen Gebiete erfordern würde. Von vornherein als sachfremd abzulehnen sind jedenfalls die Bestrebungen, die darauf hinauslaufen, die Vereinten Nationen ähnlich wie die Küstenstaaten hinsichtlich des Festlandsockels mit einer Art Bergregal auszustatten, um sie auf diese Weise bis zu einem gewissen Grade auf eine eigene finanzielle Grundlage zu stellen ${ }^{219}$. Hierbei würden nämlich lediglich die Verein-

214 Hierbei ist besonders an schädliche Rückwirkungen auf den biologischen Haushalt des Meeres zu denken, die vor allem eine Gefahr für die Fischbestände bilden würden.

215 In dieser Hinsicht hat der amerikanische Vorschlag einer International Decade of Ocean Exploration zu Recht weltweite Beachtung erfahren; vgl. hierzu auch die Rede von James Russell Wiggins in der Sitzung des Ersten Ausschusses vom 6. 11. 1968 (Englischer Text: The Department of State Bulletin vom 2. 12. 1968, S. 574). Vgl. auch UN Monthly Chronicle, Bd. 5 (1968), Nr. 11, S. $57 \mathrm{f}$.

216 Gegenwärtig sind es 126 Mitgliedstaaten; vgl. die Aufstellung in: Vereinte Nationen, Bd. 17 (1969), S. 34

217 Besonders ist hier die Frage einer Neufassung des Art. 1 der Festlandsockel-Konvention, die vom 10.6. 1969 einer Revision unterzogen werden kann, zu nennen.

218 Diese ist vor allem deshalb gefährlich, weil sie die Okkupation von Teilen des Tiefseebodens tatsächlich begünstigt.

219 Vgl. hierzu War/Peace Report, Bd. 7 (1967), Nr. 9, S. 10. 
ten Nationen an die Stelle der Einzelstaaten treten und das würde dem völkerrechtlichen Prinzip der freien Nutzung des Tiefsee-Bodens und -Untergrundes genauso widersprechen wie die Anerkennung ausschließlicher Hoheitsrechte für einzelne Staaten.

Andererseits kann die Freiheit der Ausbeutung der Naturschätze dẹr fraglichen Räume auch kaum der Bergbaufreiheit des innerstaatlichen Rechts gleichgesetzt werden; denn dort hat man es nicht mit Sachen zu tun, die im Gemeingebrauch aller stehen. Im Hinblick auf diese Rechtsnatur des Tiefsee-Bodens und -Untergrundes erscheint vielmehr eine Analogie zum nationalen Recht der Nutzung öffentlicher Sachen angebracht. Nach den Grundsätzen des deutschen Verwaltungsrechts sind hierbei Gemeingebrauch auf der einen und Sondernutzung auf der anderen Seite zu unterscheiden, wobei es neben der schlichten auch eine gesteigerte Sondernutzung gibt. Die gesteigerte Sondernutzung ist von einer besonderen Nutzungsverleihung abhängig und kann von der Entrichtung einer Benutzungsgebühr abhängig gemacht werden. Überträgt man einmal diese Grundsätze auf das Völkerrecht, so wäre die Ausbeutung der Naturschätze des Tiefsee-Bodens und -Untergrundes wegen ihres Charakters der besonderen Inanspruchnahme und des Eingriffs in die Substanz der genutzten Sachen als gesteigerte Sondernutzung anzusprechen. Hierbei würde sich de lege lata die Befugnis zur Ausbeutung direkt aus dem Völkerrecht ergeben, nämlich aus dem Prinzip der Freiheit der Meere. Anders als das System staatlicher Nutzungsverleihungen gewährt dieser Grundsatz jedoch kein ausschließliches Nutzungsrecht, sondern enthält lediglich eine Einschränkung des Gemeingebrauchs durch die Rechte anderer. Hier dürfte der Ansatzpunkt für eine an der Sache orientierte zukünftige Regelung gegeben sein. Ist doch das Fehlen ausschließlicher Nutzungsrechte, die bei den meisten Arten gesteigerter Sondernutzung vor allem aus wirtschaftlichen Gründen erforderlich sind, als Hauptgrund für die Möglichkeit von Konflikten und damit für die Unzulänglichkeit des gegenwärtigen Rechtszustandes anzusehen. Eine zukünftige Regelung der Nutzung des Tiefsee-Bodens erfordert also ein Mehr an Rechten, als sie das Völkerrecht zur Zeit gewährt. Ähnlich wie im innerstaatlichen Bereich wird sich aber die Völkergemeinschaft zur Gewährung derartiger zusätzlicher Rechte nur gegen ein der Benutzungsgebühr entsprechendes Entgelt bereitfinden. Dieses könnte gleichzeitig als Regulatif zur Verhinderung monopolistischer Tendenzen dienen, wenn es so bemessen wird, daß es die Inanspruchnahme von Sondernutzungsrechten für größere Flächen als die, welche tatsächlich in einem bestimmten Zeitraum ausgebeutet werden sollen, verhindert.

Eine derartige, auf dem Gedanken der gebührenpflichtigen Nutzungsverleihung beruhende Regelung würde sich nicht nur von der Sache her empfehlen, sondern auch den Interessen der Staaten am besten entsprechen. Das gilt einmal für die Staaten, deren Unternehmen an der Ausbeutung des Tiefsee-Bodens und -Untergrundes beteiligt sind. Für diese Unternehmen würde nämlich ein System von Nutzungsverleihungen der skizzierten Art im Gegensatz zur heutigen Rechtslage sichere Kalkulationsgrundlagen schaffen und sowohl einem ruinösen Wettbewerb als auch dem Mißbrauch wirtschaftlicher Macht zur Ausschaltung des Wettbewerbs entgegenwirken. Sie läge aber auch im Interesse der übrigen Staaten; denn sie würden über die Verteilung der Nutzungsgebühren indirekt an der Ausbeutung des Tiefsee-Bodens teilhaben. Langfristig wäre allerdings eine bloß finanzielle Beteiligung nicht im wohlverstandenen Interesse dieser Staaten, zu 
denen nicht nur die Entwicklungsländer zu rechnen sind. Vielmehr ist anzustreben, sie - wie bei der Entwicklungshilfe auch - allmählich aus dem Status des lediglich Nehmenden herauszuführen. Dazu wird es erforderlich sein, daß sie durch Ausbildung entsprechender Fachkräfte sowie durch Kapitalhilfe bei der Gründung entsprechender Unternehmen in die Lage versetzt werden, den Boden und Untergrund der Tiefsee selbständig und eigenverantwortlich ebenfalls $z u$ nutzen.

Es leuchtet ein, daß eine derartige Regelung eine Organisation erfordert, die mit echten Verwaltungsbefugnissen ausgestattet ist. Damit eine solche Organisation überhaupt von den Staaten akzeptiert wird, wird man allerdings zunächst eine gebundene Verwaltung, die im wesentlichen Registrierungsfunktionen wahrnimmt, einer Ermessensverwaltung vorzuziehen haben. Außerdem wird in irgendeiner Form die Möglichkeit gerichtlichen Rechtsschutzes geschaffen werden müssen. Die genannten internationalen Verwaltungsaufgaben müßten aber nicht unbedingt auch einer internationalen Organisation übertragen werden. Man könnte vielmehr daran denken, daß die Küstenstaaten, welche als Anlieger des Hohen Meeres an der Nutzung des Tiefsee-Bodens besonders interessiert sind und meist schon über eine sachkundige Verwaltung verfügen, solche Befugnisse als Mandatar der Völkergemeinschaft ausüben. Hierbei bestände allerdings die Gefahr, daß die betreffenden Staaten in der Praxis die Unternehmen anderer Staaten bei der Vergabe der Nutzungsrechte benachteiligen würden. Der besonderen Interessiertheit der Küstenstaaten könnte man auch dadurch Rechnung tragen, daß ihnen in regionalen internationalen Organisationen, deren Kompetenzen auf bestimmte Weltmeere oder Teile von diesen beschränkt wären, besondere Rechte eingeräumt würden. Derartige Organisationen oder eine einzige, die für alle Weltmeere zuständig wäre, könnten entsprechend dem ursprünglichen Vorschlag Maltas auch außerhalb der Vereinten Nationen errichtet werden. Sofern es überhaupt gelingen wird, den Boden und Untergrund der Tiefsee unter eine internationale Verwaltung zu stellen, dürfte es sich jedoch empfehlen, auf der praktischen Arbeit aufzubauen, die von den Vereinten Nationen auf dem maritimen Sektor schon jetzt geleistet wird. In welcher organisatorischen Form das am besten $\mathrm{zu}$ geschehen hat, läßt sich zur Zeit noch nicht beurteilen ${ }^{220}$. In jedem Falle müßten auch die Staaten, die nicht Mitglied der Vereinten Nationen sind, gleiche Mitspracherechte erhalten, damit eine entsprechende Regelung für sie akzeptabel wäre.

Abschließend ist davor zu warnen, schon für die nahe Zukunft eine perfekte Regelung aller mit der Nutzung des Tiefsee-Bodens und -Untergrundes zusammenhängenden Fragen anzustreben. Etwaige Vereinbarungen müßten sich vielmehr zunächst darauf beschränken, im wesentlichen die gegenwärtige Rechtslage zu kodifizieren und sie nur geringfügig in der angedeuteten Richtung zu modifizieren. Ein derartiges Verfahren würde auf lange Sicht nicht nur die Schaffung einer arbeitsfähigen internationalen Verwaltung begünstigen, sondern wäre auch am besten geeignet, den Grundsatz aufrechtzuerhalten, der die Grundlage aller zukünftigen Regelungen bleiben muß: Die Freiheit der Meere.

220 Man wird jedoch hierbei die Bevorrechtigung bestimmter Staaten durch ein Vetorecht beseitigen müssen und auf der anderen Seite der unterschiedlichen Interessiertheit der einzelnen Staaten durch Abkehr von dem Prinzip des gleichen Stimmrechts Rechnung zu tragen haben. Auf diesen Grundgedanken beruht auch der vom Center for the Study of Democratic Institutions in Santa Barbara, Kalifornien, ausgearbeitete Entwurf einer Satzung für eine internationale Behörde für die friedliche Nutzung des TiefseeBodens; vgl. Reilly, a. a. O., S. 7. 